\title{
Primed to Sleep: The Dynamics of Synaptic Plasticity Across Brain States
}

\author{
Julie Seibt ${ }^{1 *}$ and Marcos G. Frank ${ }^{2}$ \\ 1 Surrey Sleep Research Centre, University of Surrey, Guildford, United Kingdom, ${ }^{2}$ Department of Biomedical Sciences, \\ Elson S. Floyd College of Medicine, Washington State University Spokane, Spokane, WA, United States
}

It is commonly accepted that brain plasticity occurs in wakefulness and sleep. However, how these different brain states work in concert to create long-lasting changes in brain circuitry is unclear. Considering that wakefulness and sleep are profoundly different brain states on multiple levels (e.g., cellular, molecular and network activation), it is unlikely that they operate exactly the same way. Rather it is probable that they engage different, but coordinated, mechanisms. In this article we discuss how plasticity may be divided across the sleep-wake cycle, and how synaptic changes in each brain state are linked. Our working model proposes that waking experience triggers short-lived synaptic events that are necessary for transient plastic changes and mark (i.e., 'prime') circuits and synapses for further processing in sleep. During sleep, synaptic protein synthesis at primed synapses leads to structural changes necessary for long-term information storage.

Keywords: sleep, experience, plasticity, tagging, excitability, priming, consolidation

\section{OPEN ACCESS}

Edited by:

Sara J. Aton,

University of Michigan, United States

Reviewed by:

Sidarta Ribeiro,

Federal University of Rio Grande do

Norte, Brazil

Barbara E. Jones,

McGill University, Canada

*Correspondence:

Julie Seibt

j.seibt@surrey.ac.uk

Received: 11 October 2018

Accepted: 09 January 2019

Published: 01 February 2019

Citation:

Seibt J and Frank MG (2019) Primed to Sleep: The Dynamics of Synaptic Plasticity Across Brain States. Front. Syst. Neurosci. 13:2. doi: 10.3389/fnsys.2019.00002

\section{INTRODUCTION}

Experience-dependent plasticity, including memory, is divided temporally into an induction (encoding) and consolidation phase. A general consensus in the field is that while encoding of new information occurs during wakefulness, sleep integrates and stabilizes the resulting plastic changes (i.e., consolidation) (Frank and Benington, 2006; Rasch and Born, 2013). This would be adaptive because experience would not trigger immediate consolidation of all incoming information, and thus avoid simultaneous and complex regulation of different cascades of information storage (Redondo and Morris, 2011). New information processing and storage in the brain are highly complex and dynamic processes that involve changes at different levels, from single synapses and molecules to entire circuits. At the single neuron level, this translates into waves of posttranslational protein modifications and new gene expression that ultimately promote long-term stabilization of changes in synaptic strength (Flavell and Greenberg, 2008). These processes likely involve different but interdependent mechanisms that are divided across wakefulness and sleep. They are likely to be different because wake and sleep are fundamentally different brain states. They should also be interdependent to ensure that information is detected, encoded and consolidated across brain states.

While existing theories on sleep function posit different roles for wake and sleep in experiencedependent plasticity, they do not systematically distinguish between mechanisms known to participate in plasticity induction and consolidation. For example, synaptic potentiation, which has been proposed to occur during either wake (Tononi and Cirelli, 2014) or sleep (Rasch and Born, 2013), is a dynamic process that is initially labile and relies on specific molecular mechanisms for its long lasting expression. There is also an abundant literature showing 
that both wake and sleep promote molecular mechanisms of synaptic plasticity (for recent reviews, see da Costa Souza and Ribeiro, 2015; Puentes-Mestril and Aton, 2017; Almeida-Filho et al., 2018; Navarro-Lobato and Genzel, 2018). What is less clear is how the mechanisms of plasticity induction and consolidation are divided across brain states. Therefore, it is important to delineate the plastic processes that occur in different brain states and to determine how changes in one brain state link to and influence changes in another.

In this paper, we discuss new ideas about how plasticity mechanisms are divided across the sleep-wake cycle and how plastic events in one brain state set in motion plastic changes in another. More specifically we propose that waking experience promotes two parallel events that recruit shared mechanisms: transient plastic changes and the priming of neurons for further modification in sleep. Priming refers to experiencedependent mechanisms that mark neurons in a synapse- and circuit-specific manner for further modifications. During sleep, reactivation of primed circuits leads to more permanent changes in synaptic weights via stabilization of structural plasticity. Structural plasticity stabilization involves a set of localized molecular mechanisms that transforms the transient priming instructions into lasting morphological changes at synapses. We conclude with predictions, open questions and future directions.

\section{PLASTICITY INDUCTION DURING WAKEFULNESS: LABILE CHANGES AND NEURONAL PRIMING}

When considering experience-dependent plasticity, it is important to understand the nature and timeline of processes that underlie plasticity induction and stabilization. New experience activates a cascade of events in neurons whereby each step triggers specific molecular mechanisms necessary for the full expression of long-term synaptic plasticity. The lasting nature of plasticity-related changes in neurons is traditionally viewed to depend on activation of new gene transcription and translation (Flavell and Greenberg, 2008; Hernandez and Abel, 2008). Several molecular and anatomical studies show that waking leads to labile synaptic changes associated with the induction process. Some of these same events may also prime neurons for further modification in sleep. We discuss these ideas in more detail in the following sections.

\section{Transient Plastic Changes During Wakefulness}

Findings in vivo and in vitro indicate that the plasticity induction process triggers short-lived changes that mainly depend on post-translational modifications of existing proteins and rapid morphological alterations of dendritic spines (Lang et al., 2004; Hernandez and Abel, 2008; Bailey et al., 2015). At the molecular level, many forms of plasticity induction rely on $\mathrm{N}$-methyl-D-aspartate receptors (NMDARs) activation leading to intracellular calcium $\left(\mathrm{Ca}^{2+}\right)$ influx and rapid activation of various protein kinases [e.g., calcium/calmodulin dependent kinases (CaMKs), protein kinases A (PKA), and C (PKC), extracellular signal-regulated protein kinase (ERK)] and phosphatases [e.g., protein phosphatase 1 (PP1), calcineurin] (Ho et al., 2011). Enzymatic activation triggers two main modifications at synapses: changes in $\alpha$-amino-3-hydroxy-5methyl-4-isoxazolepropionic acid receptors (AMPARs) number and activity (Hayashi et al., 2000; Esteban et al., 2003; Yang et al., 2008) and morphological changes of spines. Experience and long-term potentiation (LTP) protocols are associated with rapid (within 1-2 h) changes in spine volume and number. These changes are transient and only a fraction of newly formed spines will persist over time (Xu et al., 2009; Yang et al., 2009). This is consistent with the idea that stabilization of structural plasticity induced by experience can take several hours to weeks, and involves both strengthening and weakening of selected synapses (Hofer et al., 2009; Xu et al., 2009; Yang et al., 2009; Sanders et al., 2012; El-Boustani et al., 2018). This initial modification of spine structure is thought to rely mainly on phosphorylationdependent changes in actin cytoskeleton dynamics rather than new protein synthesis (Lang et al., 2004; Bhatt et al., 2009; Okamoto et al., 2009; Caroni et al., 2014; Bailey et al., 2015).

In addition to these protein synthesis-independent synaptic changes, experience also rapidly induces new gene expression which is the first step toward consolidation of plastic changes in neurons (Flavell and Greenberg, 2008). In particular, gene transcription activation occurs within minutes in specific neuronal ensembles activated by experience (Minatohara et al., 2016; Lisman et al., 2018). The two main signatures of experience-dependent transcription are the phosphorylation of cAMP response element binding protein (CREB) and the transient expression of Immediate Early Genes (IEGs) (Flavell and Greenberg, 2008; Caroni et al., 2014; Minatohara et al., 2016). Collectively, those data suggest that at the molecular and structural levels, early forms of plasticity are initially fragile, require covalent change of pre-existing proteins and rapid IEG transcription, but are largely independent of translation.

Studies in animals and humans show that many forms of memory are labile and susceptible to interference until sleep occurs, after which they are resistant to further disruption (reviewed in Aton et al., 2009b). A very recent study by Wang et al. (2018) demonstrated that, compared to sleep, wakefulness globally increases phosphorylation in the brain. Interestingly, among the proteins that showed increased phosphorylation, most of them were synaptic proteins associated with pre-synaptic short-term plasticity (e.g., Syn1, Rims1), post-synaptic density structure (e.g., scaffolding proteins, actin remodeling), glutamate receptors (e.g., Grin2b/5), or inhibition of translation (e.g., AMPK) (Wang et al., 2018). In vitro measures show that extended wakefulness (i.e., sleep deprivation, SD) impairs hippocampal LTP dependent on CAMP/PKA/CREB signaling, but not LTP that requires new translation (Vecsey et al., 2009). In the developing visual cortex, plasticity in vivo induced during waking is independent of translation, as inhibition of kinases critical for translation activation (i.e., mTOR, ERK, MNK) has no effect on waking plasticity (Seibt et al., 2012; Dumoulin et al., 2015). Finally, the stabilization of learning-induced spine formation and pruning in the rodent cortex does not occur during wakefulness, 
and is instead only detectable after sleep (Yang et al., 2014; Li et al., 2017). Therefore, plasticity during wakefulness is similar to 'early' forms of plasticity in vitro that are also labile and translation independent. In the next section, we will describe how these early molecular changes outline physiological processes involved in cell-wide and synapses-specific priming in neurons and circuits activated by experience.

\section{Bridging Brain States Through Priming Mechanisms During Wakefulness}

If wakefulness and sleep are partners in synaptic plasticity, how does the induction of plasticity during wakefulness lead to secondary modifications during sleep? The answer may lie in a phenomenon known as 'metaplasticity' (Hulme et al., 2013; Yee et al., 2017). Metaplasticity refers to neural changes that influence the capacity for subsequent synaptic plasticity ("plasticity of synaptic plasticity" (Abraham and Bear, 1996)). Among the various forms of metaplasticity, synaptic tagging (Frey and Frey, 2008; Redondo and Morris, 2011) and changes in neuronal excitability (Benito and Barco, 2010) provide two types of mechanisms that mark or prime synapses and neurons engaged in the learned experience, respectively. Importantly, neuronal circuits are primed according to their activation history (i.e., weak or strong) and thus allow delayed consolidation while maintaining cell- and input-specificity, as well as bidirectionality of plastic changes. Although current metaplasticity mechanisms do not consider sleep and wakefulness and have been mainly integrated into models of memory allocation (Rogerson et al., 2014; Lisman et al., 2018), it is easy to see how a similar process could provide a molecular bridge between plastic changes in one brain state and those in another (Figure 1).

\section{Synaptic Tagging}

Long-term synaptic plasticity does not appear to involve a change in the total number of synapses but is instead accompanied by the formation and loss of synapses (Popov et al., 2004; Bourne and Harris, 2011; El-Boustani et al., 2018). This is consistent with the observation that both spine formation and pruning occur across wake and sleep (Maret et al., 2011; Yang and Gan, 2012; Li et al., 2017). But how does the sleeping brain remember and select synapses for strengthening or for pruning? Here the Synaptic Tagging and Capture hypothesis (STC) (Frey and Morris, 1997; Redondo and Morris, 2011) provides an attractive framework. The STC proposes that learning creates the potential for long-term synaptic changes by setting 'tags' at remodeling synapses. Later reactivation (within hours) of the neuronal network surrounding tagged synapses promotes the capture and translation of Plasticity Related Products (PRPs) leading to a final stabilization of synaptic weight change while maintaining input-specificity (Redondo and Morris, 2011). Since tags can be positive or negative, this marks synapses for further spinogenesis/strengthening or pruning/weakening upon reactivation.

\section{Tags}

While their identity is still under investigation, tags are thought to be localized molecular processes that render synapses temporally permissive for PRPs capture (Redondo and Morris, 2011). Tags can include transient protein modifications that occur at synapses (e.g., phosphorylation/dephosphorylation). Pharmacology and genetic manipulations have shown that CaMKII $\alpha$ may act as a positive tag necessary for later LTP/spine enlargement (Okamoto et al., 2009; Redondo et al., 2010; Redondo and Morris, 2011). Due to its ability to autophosphorylate, CaMKII $\alpha$ is a strong tag candidate as its activation can last for several hours and span across different brain states. Furthermore, CaMKII $\alpha$ autophosphorylation is detectable during wake (Vyazovskiy et al., 2008) and early sleep following experience-dependent plasticity induction in the cortex (Aton et al., 2009a) and hippocampus (Blanco et al., 2015). The kinase PKA may also act as a positive tag (Young et al., 2006; Moncada et al., 2011). PKA is rapidly activated upon plasticity induction and also appears to remain active for several hours following experience (Aton et al., 2009a) or learning (Abel et al., 1997; Bourtchouladze et al., 1998). Consistent with this role, PKA inhibition during sleep only affects the potentiation, but not the depression, of neuronal activity normally seen in a physiological model of developmental plasticity in the visual cortex (i.e., ocular dominance plasticity [ODP]) (Aton et al., 2009a). Negative (or 'inverse') tags will mark synapses for synaptic weakening and include activation of phosphatases and kinase isoforms. The phosphatase calcineurin, for example, may act as inverse tag for long-term depression (LTD)/spine shrinkage induction (Zhou et al., 2004; Redondo and Morris, 2011). The CaMKII isoform CaMKII $\beta$ has also been proposed to act as inverse tag, as it can interact with negative PRPs such as Arc (Okuno et al., 2012). The function of a tag can also vary depending on its action on actin filaments. It has therefore been recently proposed that a core tagging mechanism are changes in actin dynamics (Okamoto et al., 2009; Redondo and Morris, 2011; Szabó et al., 2016).

\section{PRPs}

The complete identity of PRPs is also unknown (Figure 2 and Table 1). An important feature of PRPs is their trafficking into dendrites (Cajigas et al., 2012) where they will be available near tagged synapses for subsequent capture upon reactivation (Figures 1B, 3A). The neurotrophin BDNF, the AMPAR subunit GluR1 and the kinase PKMzeta are the best characterized positive PRPs underlying persistent forms of LTP (Sajikumar et al., 2009; Sajikumar and Korte, 2011; Panja and Bramham, 2014). PSD95, the increased expression of which at synapses is critical for persistent spine enlargement (Meyer et al., 2014), may also act as a positive PRP. Arc and Homerla may act as tags, but have also been proposed to act as negative PRPs upon delayed network reactivation (Redondo and Morris, 2011). Arc and Homerla are upregulated during wake in the cortex and hippocampus and have been linked to synaptic depression (Okada et al., 2009; Okuno et al., 2012; Jakkamsetti et al., 2013; Siddoway et al., 2014; Diering et al., 2017). The role of Arc in synaptic plasticity and memory is complex and manifold (Nikolaienko et al., 2018) but one important function at synapses is to promote internalization of AMPARs and LTD via interaction with other post-synaptic proteins such as endophilin/dynamin (Okuno et al., 2012; Wilkerson et al., 2018). 


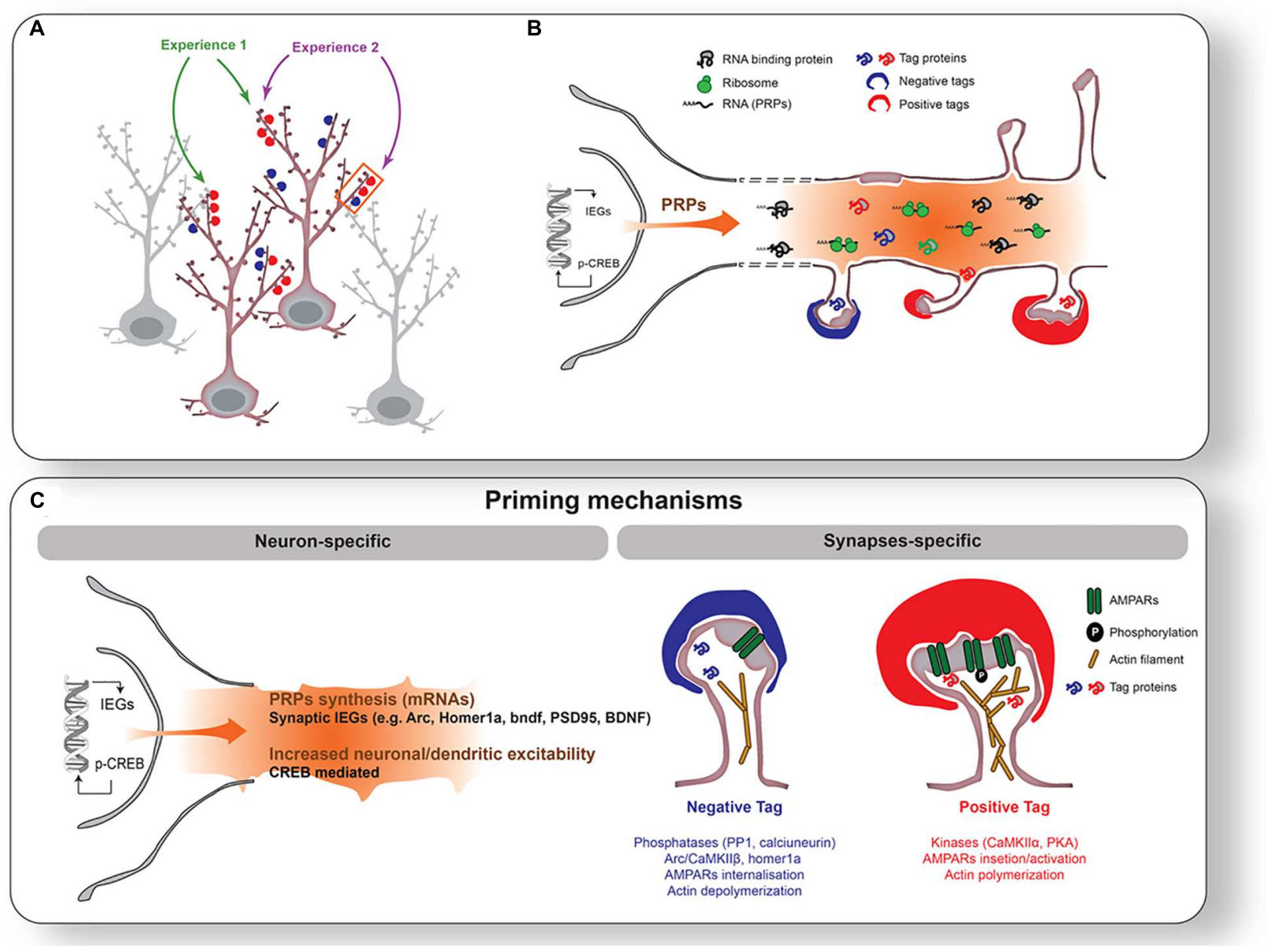

FIGURE 1 | Priming mechanisms during wakefulness. (A) Individual neurons and synapses activated by two different experiences (1 [green] and 2 [purple]). Experience 1 activates synapses onto two different neurons, while Experience 2 activates different synapses on the same neuron. In this example, Experiences 1 and 2 will stimulate one common neuron and a subset of common synapses on the same dendritic branch. Experience will increase excitability in selected neurons (highlighted with red outline) and tag synapses positively (red cap on spines) or negatively (blue cap on spines). (B) Enlargement of the segment of dendrites outlined with an orange rectangle in (A). CREB activation and IEGs expression will be triggered in activated neurons. This leads to a transcription of Plasticity Related Products (PRPs: e.g., arc, bdnf, PSD-95, Homer1a) transported to dendrites. (C) Illustration of mechanisms of neuronal (left) and synaptic (right) priming. Neuronal priming is mainly supported by CREB-dependent increase in neuronal/dendritic excitability. Synaptic priming is achieved by tagging mechanisms such as post-translational modifications of receptors, enzymes, and actin filaments.

Waking appears to be the preferred brain state for PRPs transcription and dendritic targeting of PRPs. This is suggested by two observations. First, many PRPs are synapse related IEGs (e.g., arc, homer1a, bdnf, narp) and thus rapidly transcribed in an experience-dependent manner. Second, a majority of genomewide studies report that the transcription of these mRNAs is maximal during waking and drops during sleep (Figure 2 and Table 1). Therefore, in addition to the setting of tags, the waking brain state [and/or the circadian active phase (Noya, 2018)] may globally increase the pool of dendritic PRPs in neurons activated by experience (Figure 1).

\section{Waking Changes in Intrinsic Excitability: Priming Neurons and Dendrites}

Changes in neuronal excitability are achieved by modifying intrinsic membrane conductance in neuron cell bodies or specific neuronal compartments (i.e., dendrites) activated by experience (Hulme et al., 2013; Kastellakis et al., 2015; Lisman et al., 2018). Changes in excitability are often associated with synaptic plasticity (Armano et al., 2000; Daoudal and Debanne, 2003; Frick and Johnston, 2005; Xu et al., 2005) and can prime neurons by adjusting the threshold for subsequent plasticity. While several mechanisms can lead to increased excitability, an important contributor to this process is the cAMP/CREB pathway (Benito and Barco, 2010; Rogerson et al., 2014). Activation of CREB-dependent gene expression has been shown to lower the threshold for LTP expression and increase excitability via reduction of the afterhyperpolarization (AHP) current (Lopezde Armentia et al., 2007). This CREBdependent increase in excitability is specific to neuronal circuits engaged in the learning task and enhances subsequent memory consolidation (Viosca et al., 2009; Zhou et al., 


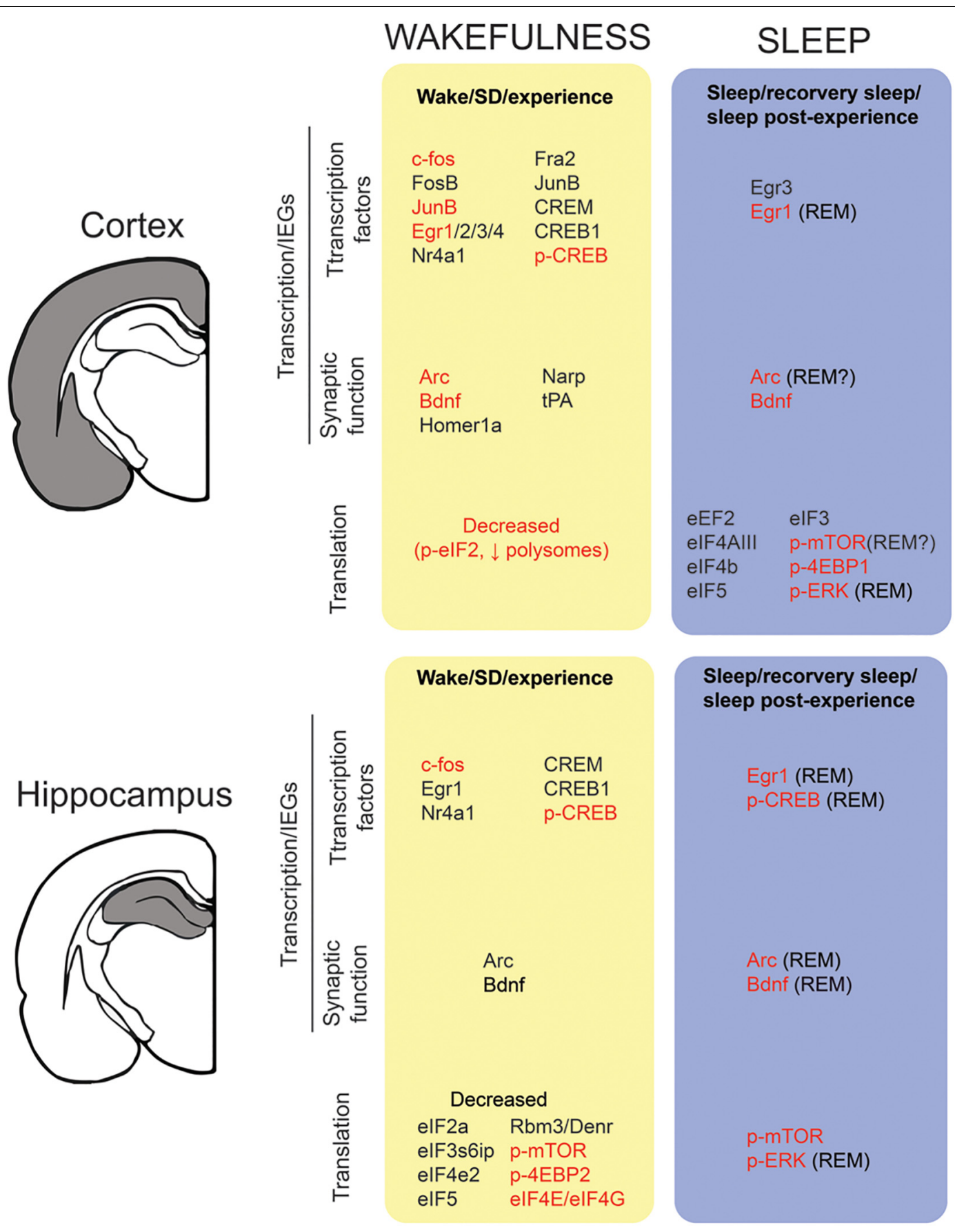

FIGURE 2 | Transcription and translation across sleep and wake in the cortex and hippocampus. We report the state-dependent regulation of (1) immediate early genes (IEGs) from the transcription factors and synaptic related genes families and (2) translation factors/activation. For details (i.e., methods, experimental design) on the studies included in this figure, refer to Tables 1, 2. To be included in this figure, a gene or protein had to show a similar trend in at least two independent studies. Genes in black represent mRNA expression. Genes highlighted in red means that expression (or activation) was also detected at the protein level.

2009). cAMP also directly activates the hyperpolarizationactivated cyclic nucleotide-gated $(\mathrm{HCN})$ channels which are important regulators of excitability (Benarroch, 2013) and are expressed in high amount in distal dendrites of pyramidal neurons. This suggests that cAMP activation may result in greater excitability within dendrites (Losonczy et al., 2008) consistent with a role of $\mathrm{HCN}$ channels in localized dendritic plasticity (Williams et al., 2007; Shah, 2014). This is further supported by a recent study showing that transient plasticity induction in single distal dendrites leads to localized increases in membrane excitability in those dendrites (Sandler et al., 2016). 
TABLE 1 | Transcription and immediate early genes (IEGs) across sleep and wake in the cortex and hippocampus.

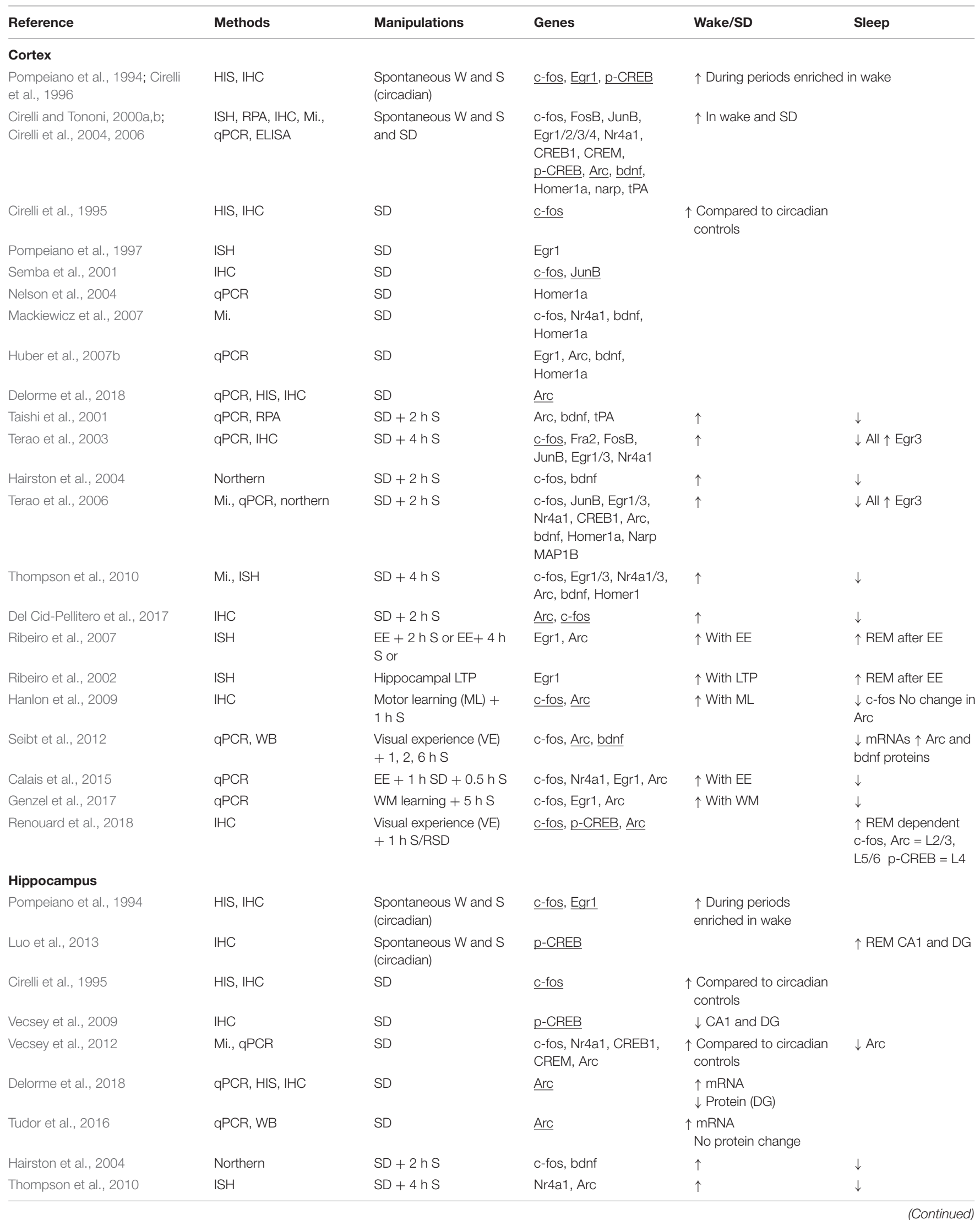


TABLE 1 | Continued

\begin{tabular}{|c|c|c|c|c|c|}
\hline Reference & Methods & Manipulations & Genes & Wake/SD & Sleep \\
\hline Taishi et al., 2001 & qPCR, RPA & $\mathrm{SD}+2 \mathrm{~h} \mathrm{~S}$ & Arc & $\uparrow$ & $\uparrow$ \\
\hline Ribeiro et al., 1999 & $\mathrm{ISH}$ & $\mathrm{EE}+2 \mathrm{~h} \mathrm{~S}$ & Egr1 & No change & $\uparrow$ REM after EE \\
\hline Ribeiro et al., 2002 & $\mathrm{ISH}$ & Hippocampal LTP & Egr1 & $\uparrow$ With LTP & No change \\
\hline Ribeiro et al., 2007 & $\mathrm{ISH}$ & $\mathrm{EE}+4 \mathrm{~h} \mathrm{~S}$ & Egr1, Arc & $\uparrow$ With EE & No change \\
\hline Ulloor and Datta, 2005 & WB & TWAA learning +6 h S & p-CREB $, \underline{\text { Arc }}, \underline{\text { bdnf }}$ & $\begin{array}{l}\uparrow \text { During } 6 \text { h post } \\
\text { TWWA, correlates with } \\
\text { REM PGO }\end{array}$ & \\
\hline Datta et al., 2008 & qPCR, WB & $\begin{array}{l}\text { TWAA learning }+3 \text { h S } \\
\text { (PGO inhibition) }\end{array}$ & $\begin{array}{l}\text { Egr1, p-CREB, Arc, } \\
\text { bdnf }\end{array}$ & $\begin{array}{l}\uparrow \text { During } 3 \text { h post } \\
\text { TWWA, dependent on } \\
\text { REM PGO }\end{array}$ & \\
\hline Calais et al., 2015 & qPCR & $E E+S$ & c-fos, Nr4a1, Egr1, Arc & $\uparrow$ With EE & $\uparrow$ REM after EE \\
\hline Genzel et al., 2017 & qPCR & WM learning $+5 \mathrm{~h} S$ & c-fos, Egr1, Arc & $\uparrow$ With WM & $\downarrow$ \\
\hline
\end{tabular}

Data reported in this table focus on changes in the cortex and hippocampus in mammals (rat, mouse, and cat). Changes in sleep-wake regulatory brain structures (e.g., hypothalamus, brainstem) and whole brain extract are not included. Waking data were restricted to periods of sleep deprivation $<8 \mathrm{~h}$. Underlined genes $=$ protein (with or without mRNA; refer to the Methods column for details) were investigated. SD, sleep deprivation; S, sleep; RSD, REM sleep deprivation; EE, enriched environment; TWAA, two-way active avoidance; WM, water maze; Mi, microarray; qPCR, quantitative PCR; IHC, immunohistochemistry; HIS, in situ hybridization; RPA, Rnase protection assay; WB, Western blot; DG, dentate gyrus; Egr1, Zif268/NGF1-A; Nr4a1, Nur77/NGF1-B.

There are several findings suggesting that neuronal priming via increased excitability occurs during wakefulness. While the underlying physiology is not clear, cortical excitability in humans has been shown to increase with time spent awake (Huber et al., 2013; Meisel et al., 2015; Ly et al., 2016). This may also explain why sleep deprivation increases the risk for seizures (Gastaut and Tassinari, 1966; Meisel et al., 2015). At the cellular level, in vivo electrophysiological recordings in rodents have shown that both spontaneous neuronal firing (Vyazovskiy et al., 2009; Miyawaki and Diba, 2016) and evoked cortical response (Vyazovskiy et al., 2013) increase with waking time, consistent with increased neuronal excitability. Similarly, in vitro recordings in rodent cortical slices support a specific rise in mEPSCs frequency after prolonged wakefulness (Winters et al., 2011), paralleled by an increased firing probability in response to an injected current (Winters et al., 2011; Yan et al., 2011). This increase in neuronal excitability after extended wakefulness has also been linked to $\mathrm{Ca}^{2+}$-dependent AHP reduction (Yan et al., 2011). At the molecular level, CREB phosphorylation in the cortex, and associated IEG transcription occurs predominantly during wakefulness (Figure 2 and Table 1). It is therefore likely that in addition to enhancing PRPs availability, CREB activation during wakefulness modifies membrane excitability within circuits and dendrites activated by experience (Lisman et al., 2018) (Figures 1A,C).

\section{BI-DIRECTIONAL PLASTICITY DURING SLEEP: CAPTURE AND TRANSLATION OF PRPs}

\section{Bi-Directional Synaptic Plasticity and Sleep}

In vivo electrophysiological recordings and dendritic spine imaging in rodents have provided evidence for bi-directional synaptic plasticity changes during sleep (reviewed in Frank and Cantera, 2014; Puentes-Mestril and Aton, 2017; Navarro-Lobato and Genzel, 2018). Recordings of neuronal spiking, an indirect measure of plasticity, shows both increased and decreased firing rates in the hippocampus and cortex during sleep. More specifically, while NREM sleep is accompanied by more heterogeneous and bi-directional changes in spiking rates (Chauvette et al., 2012; Grosmark et al., 2012; Miyawaki and Diba, 2016; Watson et al., 2016; Norimoto et al., 2018), firing rates tend to decrease across individual REM sleep episodes (Grosmark et al., 2012; Miyawaki and Diba, 2016; Watson et al., 2016). However, increased firing rate following exposure to novel perceptual experience has been shown to occur during both sleep stages in sensory cortical areas (Ribeiro et al., 2007; Aton et al., 2014; Clawson et al., 2018).

When measured after sleep, circuits can be strengthened or weakened (reviewed in Frank and Cantera, 2014). For example, sleep-dependent changes in ODP induced by monocular deprivation (as measured by evoked electrophysiological responses) involve a gain of response to the open eye and a weakening of response to the deprived eye (Aton et al., 2009a; Seibt et al., 2012). Although decreases in evoked electrophysiological responses to stimuli are reported after sleep in some rodent studies (Vyazovskiy et al., 2008), this is not always found. For example, in the cat, electrically evoked cortical responses measured during wake are larger after a period of sleep (Chauvette et al., 2012). Electrophysiological recordings also show that sleep is required for an experience-dependent form of LTP (Cooke and Bear, 2010, 2012) in the adult visual cortex in vivo (Aton et al., 2014; Durkin and Aton, 2016). Some of the heterogeneity in firing rates after sleep may also be explained by the class of neurons recorded (i.e., inhibitory vs. excitatory) and the basal level of firing rate (i.e., low vs. high) (Levenstein et al., 2017; Clawson et al., 2018).

Recent in vivo imaging studies, which provide more direct measurements of synaptic plasticity, also show complex changes in spine structure during sleep and suggest a role for sleep in 
stabilization of both spinogenesis and spine pruning (reviewed in Sigl-Glöckner and Seibt, 2018). Sleep during adolescence, when spine turn-over and pruning are high, seems to favor spine pruning in some cortical areas (Maret et al., 2011; Yang and Gan, 2012). Spine pruning during development is central to the refinement of synaptic connections in response to experience (Zuo et al., 2005; Yu et al., 2013). During adulthood, when spines are much more stable, periods of sleep following experience have been shown to be important for both synaptic strengthening/spinogenesis and synaptic weakening/spine pruning (Yang et al., 2014; Li et al., 2017), consistent with long-term structural modifications at synapses. This effect seems to mainly affect recently formed spines, leaving more stable ones relatively unaffected by sleep (Yang et al., 2014; Li et al., 2017). Furthermore, data in the developing rodents further suggest that sleep may favor the pruning of smaller spines in the cortex (Vivo et al., 2017). A similar trend has been recently described in vitro in the hippocampus in immature mice (Norimoto et al., 2018). While speculative, it is possible that the large and small spines represent the positive and negative tagging status of synapses, respectively. In the context of our model, this would further suggest that sleep might be particularly important for the final stabilization of these bi-directional transient changes in spine morphology induced during plasticity induction.

Specific cellular changes during NREM sleep may also be predictive of plastic change during REM sleep. For example, increased power in specific NREM oscillations associated with plasticity (i.e., spindles) correlate positively with changes in $\mathrm{Ca}^{2+}$ activity in cortical dendrites (Seibt et al., 2017) and CaMKII phosphorylation in hippocampal neurons (Blanco et al., 2015) during REM sleep. These results suggest that experience may affect neurons and circuits differently during both sleep stages but that these changes are most likely complementary. This is also in agreement with existing two-stage models emphasizing an important role for NREM-REM sleep in memory consolidation (see the section "Comparisons and Contrasts With Other Theories" for discussion). In the following sections, we discuss how different sleep stages may cooperate for the capture and translation of PRPs on a background of cell-specific increase in intrinsic excitability (Figure 3).

\section{NREM Oscillations for PRPs Capture (Figure 3A)}

According to current ideas about the STC, the first and necessary step toward stabilization of functional and structural plasticity is the capture of PRPs during the lifetime of the tag (minutes to hours) (Redondo and Morris, 2011). We propose that periodic reactivation of task-specific circuits during NREM oscillations, combined with priming during wake, provides an efficient mechanism for PRPs capture in a neuron- and synapse-specific manner. Localized changes in excitability can determine which dendritic segment or group of synapses are more likely to engage in synchronization patterns within a given circuit (Alarcon et al., 2006). Since reactivation affects both positively and negatively tagged synapses, this would also explain how sleep leads to bi-directional changes in synaptic plasticity. In our view, what matters is the presence of these oscillations, rather than their form which reflects differences in the underlying circuitry. NREM oscillations in general can promote synaptic capture of PRPs because they all involve a reactivation of a network and they increase in number or intensity in a use-dependent fashion.

This idea is supported by several observations. Three main NREM sleep oscillations have been implicated in experiencedependent plasticity and memory consolidation: slow-wave activity (SWA; 0.5-4 Hz) and spindles (sigma: 10-16 Hz) in the cortex, and sharp wave ripples (SPW-R; 100-200 Hz) in the hippocampus (Rasch and Born, 2013; Buzsáki, 2015; Ulrich, 2016). Although these oscillations are generated by different neuronal populations within the thalamocortical (i.e., spindles and SWA) and hippocampal (i.e., SPW-R) circuits, they all share common physiological and functional features. SWA, spindles and SPW-R have been shown to be temporally coupled across brain regions (Siapas and Wilson, 1998) and are all increased (either in number or intensity) following learning and experience (Rasch and Born, 2013; Ulrich, 2016; Norimoto et al., 2018). These use-dependent changes in NREM oscillations have been clearly demonstrated for cortical SWA and spindles in humans and animals (Vyazovskiy et al., 2000; Huber et al., 2004, 2006, 2007a; Eschenko et al., 2006; Mölle et al., 2009; Johnson et al., 2012; Cox et al., 2014). Some of these oscillations have also been shown to include coordinated reactivation of neurons and synapses previously engaged in learning tasks (Bergmann et al., 2012; Chen et al., 2013; Sadowski et al., 2016). The best evidence of this reactivation (or "replay") occurs in hippocampal cells during SPW-R (Buzsáki, 2015), but NREM replay is also reported in cortical ensembles (Euston et al., 2007; Ji and Wilson, 2007).

Waking experience has also been shown to increase synchronization and coherence in the activity of task-related neurons in the hippocampus and cortex during sleep (Gulati et al., 2014; Durkin et al., 2017; Ognjanovski et al., 2017). This increase in NREM network synchronization also correlates with plasticity measures and memory performance (Gulati et al., 2014; Ognjanovski et al., 2018). There is also evidence that the latter events are linked to neuronal priming and necessary for PRPs capture. Constitutive CREB activation (which increases excitability), via CAMKIV overexpression in mice increases NREM SWA (Steenland et al., 2010).

The direction of plastic change during sleep is likely influenced by the neurons' recent waking activity history, which in turn determines the setting of different tags. For example, SPW$\mathrm{R}$ during sleep appears to induce synaptic weakening in vivo only in neurons that were not engaged in a previous novel experience (Norimoto et al., 2018). Similarly, only neurons that are highly responsive during a motor task will show increased SWA spiking coherence during subsequent sleep (Gulati et al., 2014). In addition, while spindle activity has been linked to increased plasticity in vitro (Rosanova and Ulrich, 2005) and in vivo (Timofeev et al., 2002), more recent data also show that spindles predict global decreases in firing rate across sleep stages (Miyawaki and Diba, 2016). Consistent with a previous hypothesis (Contreras et al., 1997; Steriade and Timofeev, 2003), Seibt et al. (2017) recently demonstrated using in vivo 


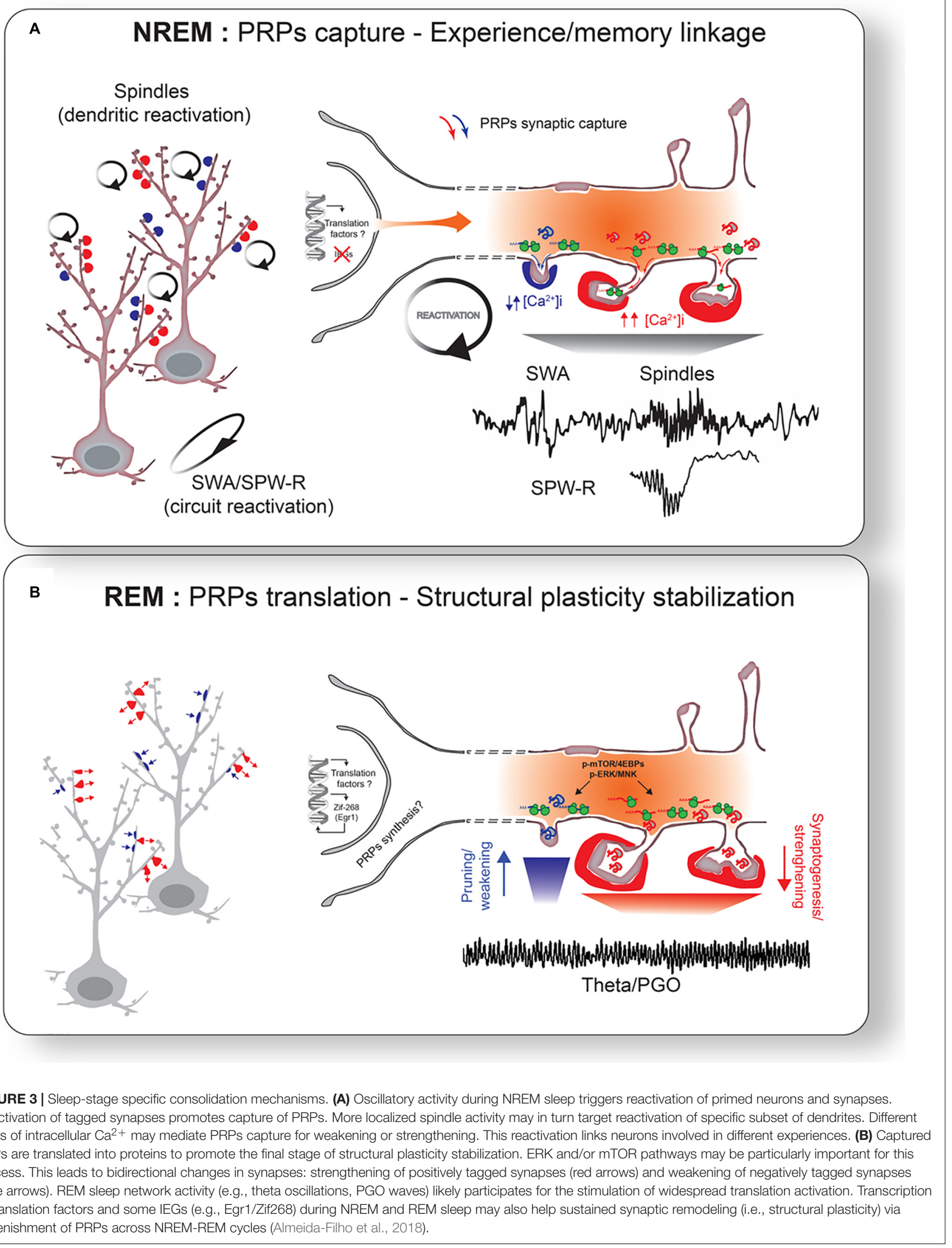


$\mathrm{Ca}^{2+}$ imaging that spindles might be particularly important for synchronized reactivation of dendritic populations.

Given its important role as a sensor of synaptic activation, different levels of intracellular $\mathrm{Ca}^{2+}$ in different groups of synapses during NREM oscillations may mediate PRPs capture weakening or strengthening. Using two-photon imaging in anesthetized mice, Chen et al. (2013) demonstrated that spines that displayed increased $\mathrm{Ca}^{2+}$ during UP states of slow oscillations represented the same population that showed $\mathrm{Ca}^{2+}$ increased during previous sensory evoked responses. Although performed in anesthetized mice, this supports the idea that synaptic tags are set during waking and captured during subsequent NREM sleep. Consistent with bi-directional plasticity changes during NREM sleep, it was recently shown that individual cortical dendrites display both increased and decreased $\mathrm{Ca}^{2+}$ activity during spindles (Seibt et al., 2017). This further suggests that local changes in $\mathrm{Ca}^{2+}$ levels during spindles may trigger intracellular mechanisms that favor both potentiation and depression in a dendrite-specific manner.

\section{REM Sleep Translation of PRPs Stabilizes Structural Plasticity}

Recent studies using two-photon imaging of single dendritic spines in mice provide direct evidence that sleep stabilizes experience-dependent structural plasticity during development and adulthood (Yang et al., 2014; Li et al., 2017). In both studies, lack of sleep disrupted both motor learning and structural plasticity stabilization. As mentioned before, an important step for the stabilization of labile into more permanent synaptic changes is new protein synthesis. More specifically, localized mRNA translation near/at synapses is a key mechanism neurons use to promote synapse-specific structural modifications during development and adulthood (Holt and Schuman, 2013). Our model proposes that, while experience-dependent PRPs transcription occurs predominantly during wake, the final translation of PRPs transcripts necessary for synapse-specific structural plasticity stabilization occurs during REM sleep (Figure 3B).

Translation activation in the brain is specifically enhanced during sleep (Table 2) and is accompanied by increased expression of PRPs proteins (Figure 2). Among the multiple pathways involved in translation regulation for plasticity and memory, one important step is activation of the eukaryote initiation factor 4E (eIF4E) resulting in translation initiation activation (Richter and Sonenberg, 2005). Two main pathways can lead to eIF4E activation: the mammalian target of rapamycin (mTOR)/4E-BPs and ERK/Mnk1 pathways (Banko and Klann, 2008). In addition to showing increased cortical and hippocampal activation during periods dominated by sleep (Eckel-Mahan et al., 2008; Seibt et al., 2012; Vecsey et al., 2012; Dumoulin et al., 2015; Luo et al., 2013; Tudor et al., 2016; Diering et al., 2017), inhibition of these pathways in the visual cortex of cats during sleep impairs the consolidation of plastic changes during ODP (Seibt et al., 2012; Dumoulin et al., 2015). A similar inhibition during waking had no effect on the labile changes triggered by monocular deprivation (Seibt et al., 2012; Dumoulin et al., 2015). Furthermore, inhibition of mTOR signaling during sleep prevents the enhancement of synaptic potentiation and reverses the depression in visual circuits normally seen during ODP (Seibt et al., 2012). This is consistent with a role for translation in stabilization of bi-directional structural plastic changes. Finally, memory impairment induced by sleep deprivation can be rescued by enhancing $4 \mathrm{E}-\mathrm{BP} 2$ activity in the hippocampus of sleep deprived mice (Tudor et al., 2016).

These results in mice and cats suggest that the increase in translation initiation during sleep is particularly critical for brain plasticity and memory consolidation. But are PRPs actually translated during sleep? In contrast to their transcripts, protein expression of several PRPs increase or remain at high

TABLE 2 | Translational activity in the cortex and hippocampus across sleep and wake.

\begin{tabular}{|c|c|c|c|c|c|c|}
\hline Reference & Methods & Area & Manipulations & Measures & Wake/SD & Sleep \\
\hline Cirelli et al., 2004 & Mi. & Cortex & $\begin{array}{l}\text { Spontaneous W and S } \\
\text { and SD }\end{array}$ & eEF2, elF4AIII & & $\uparrow$ \\
\hline Mackiewicz et al., 2007 & Mi. & Cortex & SD & eEF2, elF4b, elF5, elF3 & & $\uparrow$ \\
\hline Naidoo et al., 2005 & Ribosome profiling & Cortex & $\mathrm{SD}$ & General translation & $\downarrow$ Polysomes & \\
\hline Naidoo et al., 2008 & WB & Cortex & $\mathrm{SD}$ & p-elF2 & $\uparrow(\downarrow$ Translation activity) & \\
\hline Seibt et al., 2012 & WB & Cortex & $\begin{array}{l}\text { Visual experience }+1 \text {, } \\
2,6 \text { h S }\end{array}$ & $\mathrm{p}-4 \mathrm{EBP} 1, \mathrm{p}-\mathrm{eEF} 2$ & & $\uparrow @ 1-2$ h sleep \\
\hline Renouard et al., 2018 & $\mathrm{IC}$ & Cortex & $\begin{array}{l}\text { Visual experience }+\mathrm{S} \\
\text { and RSD }\end{array}$ & p-mTOR & & $\uparrow$ REM dependent \\
\hline Vecsey et al., 2012 & Mi., qPCR & Hipp. & $\mathrm{SD}$ & $\begin{array}{l}\text { elF2a, elF3s6ip, elF4e2, } \\
\text { elF5, Rbm3, Denr }\end{array}$ & $\downarrow$ & \\
\hline Vecsey et al., 2012 & WB & Hipp. & $\mathrm{SD}+2.5 \mathrm{~h} \mathrm{~S}$ & $\mathrm{p}-\mathrm{mTOR}$ & $\downarrow$ & $\uparrow$ \\
\hline Tudor et al., 2016 & WB & Hipp. & $\mathrm{SD}$ & $\begin{array}{l}\text { p-mTORC1, p-4EBP2, } \\
\text { elF4E/elF4G }\end{array}$ & $\downarrow$ & \\
\hline Tudor et al., 2016 & WB & Hipp. & $\mathrm{SD}$ & Puromycin (SUnSET) & $\downarrow$ & \\
\hline
\end{tabular}

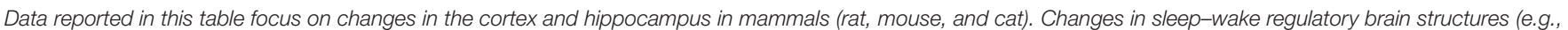

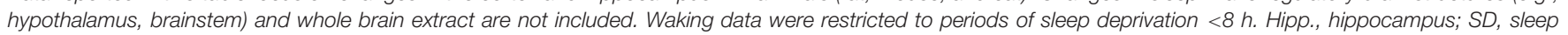
deprivation; S, sleep; RSD, REM sleep deprivation; Mi, microarray; qPCR, quantitative PCR; IHC, immunohistochemistry; WB, Western blot. 
levels during sleep in the hippocampus and cortex [i.e., BDNF, Arc, PSD95, Glur1; Figure 2 and (Ulloor and Datta, 2005; Seibt et al., 2012; Dumoulin et al., 2015; Del Cid-Pellitero et al., 2017; Renouard et al., 2018)]. Inhibition of mTOR and ERK signaling during sleep also decreases PRPs protein levels (Seibt et al., 2012; Dumoulin et al., 2015) suggesting a regulation of expression at the translational level. Activation of translation initiation and increased protein expression of some PRPs during sleep are also more pronounced at synapses supporting a synaptic-specific mechanism (Seibt et al., 2012).

REM sleep appears to be a preferred time for PRPs translation and structural plasticity. In mice, sleep-dependent structural plasticity is promoted by REM sleep during development and after learning (Li et al., 2017). Enzymes regulating translation and expression of PRPs proteins during sleep seem to also depend specifically on REM sleep. In the mouse hippocampus, the increase in ERK phosphorylation during the light (rest) phase (Eckel-Mahan et al., 2008) is maximal after a period rich in REM sleep (Luo et al., 2013). REM sleep deprivation in cats significantly decreases cortical ERK phosphorylation (Bridi et al., 2015). The cellular mechanisms by which REM sleep promotes translation are not known but may be supported by the specific network activity occurring during that stage. In the hippocampus, increased Arc and BDNF proteins after learning correlates with amounts of REM sleep pontine-geniculateoccipital waves (PGO) (Ulloor and Datta, 2005) (Table 1). Protein synthesis in dendrites of hippocampal CA1 neurons can be elicited in vitro with electrical stimulation in the theta $(4-10 \mathrm{~Hz})$ range (Feig and Lipton, 1993). Interestingly, dendritic protein synthesis in this model was dependent on pharmacological activation of muscarinic receptors, suggesting a role for the high cholinergic tone during REM sleep in translation activation at synapses. This observations are consistent with recent in vivo data showing an important role for REM sleep theta oscillations for memory consolidation (Boyce et al., 2016; Ognjanovski et al., 2017). Furthermore, both synaptic potentiation and depression can be elicited depending on the theta oscillatory phase (i.e., peak vs. through) at which electrical stimulation is applied (reviewed in Poe et al., 2010).

\section{IMPLICATIONS OF THE MODEL}

\section{Selection and Association of Memories During Sleep}

Immediate activation of consolidation upon learning is not optimal at the cellular and system levels. As discussed in Redondo and Morris (2011), consolidation of successive experiences at the time of encoding would result in superimposed activation of multiple cellular consolidation cascades within neurons. This would require extremely tight temporal regulation and high energy demands. This would also prevent selection of salient information and experience as all incoming stimuli would be stored (creating interference and a signal-to-noise problem). This problem, albeit expressed in different ways, was recognized many decades ago by scientists interested in the role of sleep in memory consolidation (reviewed in Alger et al., 2015). Sleep theoretically solves the problem as incoming stimuli are dampened and an internal reactivation of primed circuits ensures a very high signalto-noise ratio during the consolidation process.

An advantage of the STC model is that cellular consolidation mechanisms are triggered within successive check points in time by binding significant experiences within shared circuits and neurons using shared cellular pathways. We propose in our model that these check points occur in sleep, when the brain is partially disengaged from incoming information and experience. This is consistent with the idea that memories are not just consolidated during sleep but are also actively reorganized to help cognitive processes such as generalization (Stickgold and Walker, 2013) or creative thinking and problem solving (Lewis et al., 2018). The ways by which sleep may achieve this is not clear but mechanisms of selective "memory triage" (Stickgold and Walker, 2013) and network association (Cai et al., 2009) have been proposed. Linked to this idea, part of the memory consolidation process involves the integration of new experience into pre-existing memory engrams (Rasch and Born, 2013) which would require the sharing and association of common circuits. While some theories have implicated REM sleep for memory association (Lewis et al., 2018), we propose that this process may particularly benefit from PRPs capture during NREM sleep (Figure 3A). The STC model and CREBdependent increases in neuronal excitability have been proposed to facilitate associative memory (i.e., memory allocation) through the activation of shared circuits and synapses by experiences close in time (Govindarajan et al., 2006; Silva et al., 2009; Redondo and Morris, 2011; Rogerson et al., 2014; Lisman et al., 2018). If two experiences activate partially overlapping circuits, this leads to the tagging of synapses close in space (e.g., clustered on the same dendrites) and the co-activation of some neurons shared by these experiences (Figure 1A). During subsequent NREM sleep reactivation, different experiences can then be linked throughout the network. Enhanced CREB-dependent excitability will bias these neurons to be reactivated together during sleep and favor their linkage (Lisman et al., 2018). Similarly, synapses activated at close proximity will share the same type of tags and PRPs and will more likely strengthen (or weaken) in clusters, an important mechanism of memory allocation and storage (Rogerson et al., 2014; Kastellakis et al., 2015).

\section{Linking Synaptic Plasticity and Sleep Homeostasis}

Our model provides a new way to connect waking experience to sleep homeostasis. As discussed by Benington, any proposed function of sleep should describe how the progress of that function determines sleep need (Benington, 2000). In our model, neurons primed during waking experience will express more (or more intense) modulation by NREM sleep oscillations. Over the course of the sleep period, this leads to the capture, translation, and removal of the priming elements, which also reduces the electrophysiological metrics of sleep homeostasis. Thus, in contrast to other hypotheses linking, for example, NREM SWA to plasticity (Tononi and Cirelli, 2003, 2006), heightened SWA 
is not caused by stronger synapses in wakefulness, nor does it result only in synaptic weakening during sleep. SWA increases are instead caused by the priming of neurons differentially engaged during waking experience. As this priming includes positive and negative tagging, subsequent increases in NREM SWA lead to synaptic weakening and strengthening, depending on the synaptic tag. If this is true, one would predict that changes in priming (i.e., excitability and tags) parallel changes in sleep need. There is evidence to support this idea. Increased synaptic phosphorylation, which is involved in synaptic tagging according to our model (see the section "Tags"), parallels increases in sleep need and decreases during sleep (Wang et al., 2018). PRPs transcript levels generally are maximal during waking and then decline during sleep (Figure 2 and Table 1). Several IEGs show a peak and decline in their cortical expression following SD and recovery sleep that parallels the time constant for the discharge of sleep homeostasis (as measured by SWA) (Gerstner et al., 2016). In addition, some of the more dramatic sleep phenotypes in mutant animals result from changes in membrane excitability [e.g., potassium channels in drosophila (Cirelli et al., 2005; Bushey et al., 2007; Koh et al., 2008; Wu et al., 2014) and mice (Espinosa et al., 2004; Douglas et al., 2007)].

\section{Comparisons and Contrasts With Other Theories}

The goal of this article is not to exhaustively review all other theories about sleep and plasticity. However, it is useful to put our theoretical model in context. Other theorists have proposed roles for REM and NREM sleep in synaptic plasticity and memory consolidation. For example, at a systems level, it has been proposed that NREM sleep oscillations transfer and propagate memory traces from the hippocampus to neocortical areas (Ribeiro and Nicolelis, 2004; Rasch and Born, 2013; NavarroLobato and Genzel, 2018). REM sleep episodes could then promote consolidation of the transferred engram at the molecular level, mainly via transcriptional events (Ribeiro and Nicolelis, 2004; Rasch and Born, 2013; Grønli et al., 2014; Navarro-Lobato and Genzel, 2018). Some models also include a role for translation during sleep (Grønli et al., 2014; Navarro-Lobato and Genzel, 2018). However, unlike our model, this is primarily linked to NREM sleep and promotes global restorative biogenesis and local synaptic strengthening (Grønli et al., 2014).

Our model is broadly compatible with these ideas, but distinct in important ways. We propose that the bulk of transcriptional events occur during waking and is necessary for PRP synthesis at the transcriptional, not translational level. We focus on synaptic changes that may accompany systems level changes, thus our ideas are not incompatible with the transfer of information from the hippocampus to the cortex. We add to the proposed function of NREM sleep oscillations in that we suggest PRP capture at selected synapses in reactivated circuits (regardless of brain structures). In contrast to other ideas positing different roles for REM and NREM sleep in plasticity (Crick and Mitchison, 1983; Giuditta et al., 1995; Rasch and Born, 2013; Giuditta, 2014; Almeida-Filho et al., 2018; Navarro-Lobato and Genzel, 2018), our ideas are based on current ideas about metaplasticity, rather than uniform processes that drive plasticity in one (net) direction, or transcriptional events only. Our model also differs in the description of priming mechanisms that link plastic changes in waking with subsequent changes in sleep.

Our model also differs from the 'Synaptic Homeostasis Hypothesis (SHY)' which proposes that sleep weakens synapses while sparing others (a process referred to as 'down-selection'), resulting in a 'net' weakening of synapses after sleep. This type of plasticity has also been termed 'downscaling' (Tononi and Cirelli, 2003) and described in terms similar to homeostatic plasticity (Turrigiano, 2008). Although SHY allows for some synapses to become stronger during sleep, this occurs under special (e.g., non-physiological) conditions, and therefore is not a major aspect of SHY (Tononi and Cirelli, 2014). Finally, according to SHY 'protection' from down-selection does not involve an absolute increase in synaptic strength; merely a relative change compared to the net downscaling of other synapses in sleep (Tononi and Cirelli, 2014; Cirelli and Tononi, 2015). Our model instead states that synaptic strengthening is just as likely to occur as weakening during sleep (depending on prior waking experience), is not necessarily relative to other synapses, does not require 'net' synaptic downscaling and reflects physiological and adaptive processes.

This does not make our model incompatible with synaptic homeostatic adjustments during sleep. Some evidence cited in support of SHY may be explained by circadian rhythms rather than sleep (Frank and Cantera, 2014). Other findings suggest that some forms of homeostatic plasticity may only occur during wakefulness (Hengen et al., 2016). Some synaptic changes ascribed to 'net' downscaling may instead reflect the influence of negative tags and PRPs as we describe. Nevertheless, homeostatic adjustments of synapses during sleep may occur but in a manner that more generally restores set-points of activity and synaptic weight upward or down-ward depending on the neuron (Watson et al., 2016; Levenstein et al., 2017). In addition, as shown recently in a study of inhibitory and excitatory receptors on the soma of cortical principal neurons (Del CidPellitero et al., 2017), homeostatic scaling in sleep could provide a global means of adjusting excitability. In this context, this might reflect a sleep-dependent and bi-directional restorative process, reflecting the neurons' previous waking history. This homeostatic process would not interfere with Hebbian synaptic plasticity on individual synapses, neurons or circuits, as originally proposed (Turrigiano, 2008).

\section{LOOKING INTO THE FUTURE: OPEN QUESTIONS AND FUTURE DIRECTIONS}

According to our model, labile forms of plasticity are induced when we are awake and are consolidated into more permanent forms while we sleep. Waking plasticity involves transient plastic changes and priming mechanisms (changes in excitability and synaptic tagging). Waking plasticity also includes transcription and dendritic targeting of PRPs (i.e., IEGs) for synaptic capture during sleep. Plasticity during sleep promotes capture and translation of PRPs at synapses for stabilization of structural 
plasticity. Our model, informed by the STC model and new discoveries regarding priming, provides a molecular bridge between plastic changes induced in one state (wakefulness) and the other (sleep). Although speculative, this model explains a number of disparate findings in the field and leads to falsifiable predictions.

\section{Experimental Considerations, Predictions, and Unanswered Questions Experimental Considerations}

In this article, we draw on many sources of data, ranging from in vitro to in vivo experiments, and studies in many different animal species often in different brain regions. It is important to consider some general caveats in how one interprets these data. Many experiments use SD as a model of the natural waking brain state. $\mathrm{SD}$, however, can increase stress levels and stress hormones can influence metaplasticity (Schmidt et al., 2013), transcription and translation regulation (Finsterwald and Alberini, 2014; Grønli et al., 2014) as well as structural plasticity (Spruston, 2008; Liston and Gan, 2011). Furthermore, while waking plasticity may be linked to sleep as we and others (Tononi and Cirelli, 2014; Wang et al., 2018) propose, SD may affect neuronal function in a different and more global manner leading to activation of pathways unrelated to plasticity (Naidoo, 2012; Vyazovskiy and Harris, 2013). It will therefore be critical in future experiments to minimize and control for side effects due to enforced wakefulness.

Another important consideration is the interaction of circadian rhythms with the sleep-wake cycle. Biological clocks can influence sleep, transcription and translation regulation, as well as functional and structural plasticity (Frank and Cantera, 2014). For example, diurnal oscillations in ERK phosphorylation and corticosterone levels directly influence learning capacity (Eckel-Mahan et al., 2008) and structural plasticity (Liston and Gan, 2011; Liston et al., 2013), respectively. Circadian rhythmicity has also been shown to contribute to changes in levels of neuronal excitability (discussed in Frank and Cantera, 2014; Frank, 2016). It will thus be critical to clarify the respective role of biological rhythms (i.e., sleep-wake and circadian cycles) and/or their synergistic effect, on any cellular and molecular mechanisms investigated.

Some of the strongest evidence of sleep's role in brain plasticity comes from developing animals. It is well established that plasticity in the developing brain differs not only in degree, but kind, from plasticity in the adult brain. One example is plasticity during critical periods, when intracortical inhibition plays a much larger role than it does in the adult brain (Frenkel and Bear, 2004; Espinosa and Stryker, 2012). Compared to adulthood, the developing brain also exhibits higher spine turnover accompanied by an overall programs of enhanced synaptogenesis followed by synaptic pruning (Bhatt et al., 2009). The amounts, brain activity and homeostatic regulation of sleep also undergo dramatic changes in development (Davis et al., 1999). REM sleep, for example, is maximal at ages when waking experience is minuscule and may even be present without NREM sleep (Davis et al., 1999). This challenges predictions and assumptions of any model of sleep-dependent plasticity, including our own. Therefore, it is possible that not all findings obtained from developing animals will generalize across the lifespan. Finally, a major problem in any in vivo research is the methodology used to measure the physiological read-out. In the case of synaptic plasticity, molecular and electrophysiological techniques are by far the leading approaches. However, many of these measures are indirect [e.g., firing rate (Frank and Cantera, 2014)] and the results can be interpreted in different ways. This is because many of the molecular markers of plasticity are involved in different cellular functions and shared among various intracellular pathways. A notable example is Arc, a key regulator of long-term plasticity and memory implicated in LTP, LTD, synaptic homeostasis, and regulation of transcription (Minatohara et al., 2016; Nikolaienko et al., 2018). Therefore, changes in Arc observed after sleep could reflect several different processes. Given the increasing evidence that sleep is involved in subtle and synapse-specific regulation of plasticity, future experiments may greatly benefit from advances in in vivo imaging techniques that, combined with genetic tools and electrophysiological approaches, will allow scientists to address this issue in a more direct manner (Sigl-Glöckner and Seibt, 2018).

\section{Predictions}

Our model proposes that wake and sleep support different, but complementary, mechanisms which together lead to the full expression of long-term synaptic plasticity. This leads to several predictions:

- If neuronal priming is related to sleep need, then it should be proportional to time spent awake and should reverse as sleep need discharges. This prediction is supported by some evidence, but this should be investigated in more detail using appropriate methods for cellular (i.e., intrinsic excitability measures) and molecular (i.e., tag and PRPs) correlates of priming.

- If NREM oscillations are necessary for the synaptic capture of PRPs, manipulating these oscillations should alter the synaptic mRNA content. In other words, NREM oscillation disruption should result in more PRPs in the cytoplasm (soma and dendrites) compared to synapses. Conversely, enhancing these oscillations should increase synaptic PRPs content while decreasing their presence in the cytoplasm.

- If REM sleep increases synaptic mRNA translation, then manipulating REM sleep amounts should modify the synaptic proteomic content. In addition, given the high amount of REM sleep during early life (Jouvet-Mounier et al., 1970), it is expected that sleep-dependent mRNA translation is greatly enhanced in early life.

\section{Unanswered Questions}

Our model resolves some contradictions in the field and provides a novel way of thinking about how plasticity is divided across brain states. Nevertheless, working scientific 
models can oversimplify complex systems and should be cautiously interpreted. There are several findings that currently do not fit with the proposed model. While it is empirically useful to divide the synthesis, capture and translation of PRPs to wake, NREM and REM sleep, it is not clear that this division of labor always occurs. Transcription of certain IEGs (e.g., Arc, Egr1, and Egr3) also increase during REM sleep in the hippocampus and cortex (Figure 2 and Table 1). For example, the transcription factor Egr1 (i.e., Zif268) has been shown to increase during both wake and REM sleep following exposure to an enriched experience (Ribeiro et al., 1999, 2007). Zif268 is known to influence memory and LTP consolidation (Veyrac et al., 2014) and has been shown to bind to numerous targets, many of them involved in synaptic reorganization and stabilization (e.g., Arc, PSD-95, synapsin 1-3, translation factors; reviewed in Duclot and Kabbaj, 2017). One interpretation of this reactivation of PRPs synthesis is that REM sleep not only leads to consolidation in some circuits, but may also promote a re-opening of a labile, plastic period, in a manner like reconsolidation in hippocampal based memory. This secondary induction phase may also replenish primed neurons with PRPs for capture during sequences of NREM-REM sleep cycles. This might explain why REM sleep is more abundant at later stages of the sleep cycles, when the available pool of PRPs synthesized during waking may be reaching a nadir.

It is also not clear if all or most synaptic translation occurs during REM sleep. Studies using the uptake of radio-labeled amino-acids show positive correlations with NREM sleep and cortical protein synthesis (Ramm and Smith, 1990; Nakanishi et al., 1997; Czikk et al., 2003). It is possible that NREM and REM sleep both promote protein synthesis serving different functions such as macromolecule biosynthesis for cellular restorative function (Mackiewicz et al., 2007; Vyazovskiy and Harris, 2013) and structural plasticity at synapses, respectively. It is also possible that synapse-specific translation of different pools of mRNAs occurs during both the encoding (wake) and

\section{REFERENCES}

Abel, T., Nguyen, P. V., Barad, M., Deuel, T. A., Kandel, E. R., and Bourtchouladze, R. (1997). Genetic demonstration of a role for PKA in the late phase of LTP and in hippocampus-based long-term memory. Cell 88, 615-626. doi: 10.1016/S0092-8674(00)81904-2

Abraham, W. C., and Bear, M. F. (1996). Metaplasticity: the plasticity of synaptic plasticity. Trends Neurosci. 19, 126-130. doi: 10.1016/S0166-2236(96)8 0018-X

Alarcon, J. M., Barco, A., and Kandel, E. R. (2006). Capture of the late phase of long-term potentiation within and across the apical and basilar dendritic compartments of CA1 pyramidal neurons: synaptic tagging is compartment restricted. J. Neurosci. Off. J. Soc. Neurosci. 26, 256-264. doi: 10.1523/ JNEUROSCI.3196-05.2006

Alger, S. E., Chambers, A. M., Cunningham, T., and Payne, J. D. (2015). “The role of sleep in human declarative memory consolidation," in In Sleep, Neuronal Plasticity and Brain Function, eds P. Meerlo, R. M. Benca, and T. Abel (Berlin: Springer Berlin), 269-306.

Almeida-Filho, D. G., Queiroz, C. M., and Ribeiro, S. (2018). Memory corticalization triggered by REM sleep: mechanisms of cellular and systems consolidation. Cell. Mol. Life Sci. 75, 3715-3740. doi: 10.1007/s00018-0182886-9 consolidation (sleep) phases of plasticity. Rapid translation near spines increase transiently $(<2 \mathrm{~h})$ after in vivo hippocampal LTP induction (Ostroff et al., 2018) and has been hypothesized to be also part of the tagging mechanism (Redondo and Morris, 2011). Furthermore, learning and LTP protocols induce several waves of protein synthesis in vivo (reviewed in Frey and Frey, 2008). Interestingly, it seems that these waves depend on different translation regulation pathways, with the later waves $(>3 \mathrm{~h}$ ) favoring dendritic translation controlled by the 4EBPs/eIF4E complex (Panja and Bramham, 2014). This suggests that early and late plasticity may require translation that depends on proteins with different functions. Future experiments using cell-specific and compartment-specific measures of the translatome and/or proteome will be necessary to clarify the role of translation in wake and sleep stage-dependent plasticity.

\section{AUTHOR CONTRIBUTIONS}

JS wrote the manuscript and prepared the figures. MF helped to write the manuscript.

\section{FUNDING}

This research was supported by the University of Surrey/Braithwaites Foundation and the Wellcome Trust $(209099 / Z / 17 / Z)$ to JS and National Institutes of Health (EY019022, HL114161, and HD088829) to MF.

\section{ACKNOWLEDGMENTS}

We thank Giorgos Kastellakis for helpful comments on the manuscript.

Armano, S., Rossi, P., Taglietti, V., and D'Angelo, E. (2000). Long-term potentiation of intrinsic excitability at the mossy fiber-granule cell synapse of rat cerebellum. J. Neurosci. Off. J. Soc. Neurosci. 20, 5208-5216. doi: 10.1523/ JNEUROSCI.20-14-05208.2000

Aton, S. J., Seibt, J., Dumoulin, M., Jha, S. K., Steinmetz, N., Coleman, T., et al. (2009a). Mechanisms of sleep-dependent consolidation of cortical plasticity. Neuron 61, 454-466. doi: 10.1016/j.neuron.2009.01.007

Aton, S. J., Seibt, J., and Frank, M. G. (2009b). "Sleep and memory," in Encyclopedia of Life Sciences (ELS), ed. L. Chichester (Hoboken, NJ: John Wiley Sons).

Aton, S. J., Suresh, A., Broussard, C., and Frank, M. G. (2014). Sleep promotes cortical response potentiation following visual experience. Sleep 37, 1163-1170. doi: $10.5665 /$ sleep. 3830

Bailey, C. H., Kandel, E. R., and Harris, K. M. (2015). Structural components of synaptic plasticity and memory consolidation. Cold Spring Harb. Perspect. Biol. 7:a021758. doi: 10.1101/cshperspect.a021758

Banko, J. L., and Klann, E. (2008). Cap-dependent translation initiation and memory. Prog. Brain Res. 169, 59-80. doi: 10.1016/S0079-6123(07)00 004-0

Benarroch, E. E. (2013). HCN channels: function and clinical implications. Neurology 80, 304-310. doi: 10.1212/WNL.0b013e31827dec42

Benington, J. H. (2000). Sleep homeostasis and the function of sleep. Sleep 23, 959-966. doi: 10.1093/sleep/23.7.1j 
Benito, E., and Barco, A. (2010). CREB's control of intrinsic and synaptic plasticity: implications for CREB-dependent memory models. Trends Neurosci. 33, 230240. doi: 10.1016/j.tins.2010.02.001

Bergmann, T. O., Mölle, M., Diedrichs, J., Born, J., and Siebner, H. R. (2012). Sleep spindle-related reactivation of category-specific cortical regions after learning face-scene associations. NeuroImage 59, 2733-2742. doi: 10.1016/j.neuroimage. 2011.10.036

Bhatt, D. H., Zhang, S., and Gan, W.-B. (2009). Dendritic spine dynamics. Annu. Rev. Physiol. 71, 261-282. doi: 10.1146/annurev.physiol.010908.163140

Blanco, W., Pereira, C. M., Cota, V. R., Souza, A. C., Rennó-Costa, C., Santos, S., et al. (2015). Synaptic homeostasis and restructuring across the sleep-wake cycle. PLoS Comput. Biol. 11:e1004241. doi: 10.1371/journal.pcbi.1004241

Bourne, J. N., and Harris, K. M. (2011). Coordination of size and number of excitatory and inhibitory synapses results in a balanced structural plasticity along mature hippocampal CA1 dendrites during LTP. Hippocampus 21, 354373. doi: 10.1002/hipo.20768

Bourtchouladze, R., Abel, T., Berman, N., Gordon, R., Lapidus, K., and Kandel, E. R. (1998). Different training procedures recruit either one or two critical periods for contextual memory consolidation, each of which requires protein synthesis and PKA. Learn. Mem. 5, 365-374.

Boyce, R., Glasgow, S. D., Williams, S., and Adamantidis, A. (2016). Causal evidence for the role of REM sleep theta rhythm in contextual memory consolidation. Science 352, 812-816. doi: 10.1126/science.aad5252

Bridi, M. C. D., Aton, S. J., Seibt, J., Renouard, L., Coleman, T., and Frank, M. G. (2015). Rapid eye movement sleep promotes cortical plasticity in the developing brain. Sci. Adv. 1:e1500105. doi: 10.1126/sciadv.1500105

Bushey, D., Huber, R., Tononi, G., and Cirelli, C. (2007). Drosophila Hyperkinetic mutants have reduced sleep and impaired memory. J. Neurosci. Off. J. Soc. Neurosci. 27, 5384-5393. doi: 10.1523/JNEUROSCI.0108-07.2007

Buzsáki, G. (2015). Hippocampal sharp wave-ripple: a cognitive biomarker for episodic memory and planning. Hippocampus 25, 1073-1188. doi: 10.1002/ hipo. 22488

Cai, D. J., Mednick, S. A., Harrison, E. M., Kanady, J. C., and Mednick, S. C. (2009). REM, not incubation, improves creativity by priming associative networks. Proc. Natl. Acad. Sci. U.S.A. 106, 10130-10134. doi: 10.1073/pnas.090027 1106

Cajigas, I. J., Tushev, G., Will, T. J., Tom Dieck, S., Fuerst, N., and Schuman, E. M. (2012). The local transcriptome in the synaptic neuropil revealed by deep sequencing and high-resolution imaging. Neuron 74, 453-466. doi: 10.1016/j. neuron.2012.02.036

Calais, J. B., Ojopi, E. B., Morya, E., Sameshima, K., and Ribeiro, S. (2015). Experience-dependent upregulation of multiple plasticity factors in the hippocampus during early REM sleep. Neurobiol. Learn. Mem. 122, 19-27. doi: $10.1016 /$ j.nlm.2015.01.002

Caroni, P., Chowdhury, A., and Lahr, M. (2014). Synapse rearrangements upon learning: from divergent-sparse connectivity to dedicated sub-circuits. Trends Neurosci. 37, 604-614. doi: 10.1016/j.tins.2014.08.011

Chauvette, S., Seigneur, J., and Timofeev, I. (2012). Sleep oscillations in the thalamocortical system induce long-term neuronal plasticity. Neuron 75, $1105-$ 1113. doi: 10.1016/j.neuron.2012.08.034

Chen, X., Rochefort, N. L., Sakmann, B., and Konnerth, A. (2013). Reactivation of the same synapses during spontaneous up states and sensory stimuli. Cell Rep. 4, 31-39. doi: 10.1016/j.celrep.2013.05.042

Cirelli, C., Bushey, D., Hill, S., Huber, R., Kreber, R., Ganetzky, B., et al. (2005). Reduced sleep in Drosophila shaker mutants. Nature 434, 1087-1092. doi: $10.1038 /$ nature 03486

Cirelli, C., Faraguna, U., and Tononi, G. (2006). Changes in brain gene expression after long-term sleep deprivation. J. Neurochem. 98, 1632-1645. doi: 10.1111/j. 1471-4159.2006.04058.x

Cirelli, C., Gutierrez, C. M., and Tononi, G. (2004). Extensive and divergent effects of sleep and wakefulness on brain gene expression. Neuron 41, 35-43. doi: 10.1016/S0896-6273(03)00814-6

Cirelli, C., Pompeiano, M., and Tononi, G. (1995). Sleep deprivation and c-fos expression in the rat brain. J. Sleep Res. 4, 92-106. doi: 10.1111/j.1365-2869. 1995.tb00157.x

Cirelli, C., Pompeiano, M., and Tononi, G. (1996). Neuronal gene expression in the waking state: a role for the locus coeruleus. Science 274, 1211-1215. doi: $10.1126 /$ science. 274.5290 .1211
Cirelli, C., and Tononi, G. (2000a). Differential expression of plasticity-related genes in waking and sleep and their regulation by the noradrenergic system. J. Neurosci. Off. J. Soc. Neurosci. 20, 9187-9194. doi: 10.1523/JNEUROSCI.2024-09187.2000

Cirelli, C., and Tononi, G. (2000b). Gene expression in the brain across the sleep-waking cycle. Brain Res. 885, 303-321. doi: 10.1016/S0006-8993(00) 03008-0

Cirelli, C., and Tononi, G. (2015). Sleep and synaptic homeostasis. Sleep 38, 161-162. doi: 10.5665/sleep.4348

Clawson, B. C., Durkin, J., Suresh, A. K., Pickup, E. J., Broussard, C., and Aton, S. J. (2018). Sleep promotes, and sleep loss inhibits, selective changes in firing rate, response properties and functional connectivity of primary visual cortex neurons. Front. Syst. Neurosci. 14:40. doi: 10.3389/fnsys.2018.00040

Contreras, D., Destexhe, A., and Steriade, M. (1997). Intracellular and computational characterization of the intracortical inhibitory control of synchronized thalamic inputs in vivo. J. Neurophysiol. 78, 335-350. doi: 10.1152/jn.1997.78.1.335

Cooke, S. F., and Bear, M. F. (2010). Visual experience induces long-term potentiation in the primary visual cortex. J. Neurosci. Off. J. Soc. Neurosci. 30, 16304-16313. doi: 10.1523/JNEUROSCI.4333-10.2010

Cooke, S. F., and Bear, M. F. (2012). Stimulus-selective response plasticity in the visual cortex: an assay for the assessment of pathophysiology and treatment of cognitive impairment associated with psychiatric disorders. Biol. Psychiatry 71, 487-495. doi: 10.1016/j.biopsych.2011.09.006

Cox, R., Hofman, W. F., de Boer, M., and Talamini, L. M. (2014). Local sleep spindle modulations in relation to specific memory cues. NeuroImage 99, 103-110. doi: 10.1016/j.neuroimage.2014.05.028

Crick, F., and Mitchison, G. (1983). The function of dream sleep. Nature 304, 111-114. doi: 10.1038/304111a0

Czikk, M. J., Sweeley, J. C., Homan, J. H., Milley, J. R., and Richardson, B. S. (2003). Cerebral leucine uptake and protein synthesis in the near-term ovine fetus: relation to fetal behavioral state. Am. J. Physiol. Regul. Integr. Comp. Physiol. 284, R200-R207. doi: 10.1152/ajpregu.00190.2002

da Costa Souza, A., and Ribeiro, S. (2015). Sleep deprivation and gene expression. Curr. Top. Behav. Neurosci. 25, 65-90. doi: 10.1007/7854_2014_360

Daoudal, G., and Debanne, D. (2003). Long-term plasticity of intrinsic excitability: learning rules and mechanisms. Learn. Mem. 10, 456-465. doi: 10.1101/lm. 64103

Datta, S., Li, G., and Auerbach, S. (2008). Activation of phasic pontine-wave generator in the rat: a mechanism for expression of plasticity-related genes and proteins in the dorsal hippocampus and amygdala. Eur. J. Neurosci. 27, 1876-1892. doi: 10.1111/j.1460-9568.2008.06166.x

Davis, F. C., Frank, M. G., and Heller, H. C. (1999). "Ontogeny of sleep and circadian rhythms," in Regulation of Sleep and Circadian Rhythms, eds P.C. Zee and F. W. Turel (New York, NY: Marcel Dekker, Inc.), 19-80.

Del Cid-Pellitero, E., Plavski, A., Mainville, L., and Jones, B. E. (2017). Homeostatic changes in GABA and glutamate receptors on excitatory cortical neurons during sleep deprivation and recovery. Front. Syst. Neurosci. 11:17. doi: 10.3389/ fnsys.2017.00017

Delorme, J. E., Kodoth, V., and Aton, S. J. (2018). Sleep loss disrupts Arc expression in dentate gyrus neurons. Neurobiol. Learn. Mem. [Epub ahead of print]. doi: 10.1016/j.nlm.2018.04.006

Diering, G. H., Nirujogi, R. S., Roth, R. H., Worley, P. F., Pandey, A., and Huganir, R. L. (2017). Homerla drives homeostatic scaling-down of excitatory synapses during sleep. Science 355, 511-515. doi: 10.1126/science.aai8355

Douglas, C. L., Vyazovskiy, V., Southard, T., Chiu, S.-Y., Messing, A., Tononi, G., et al. (2007). Sleep in Kcna2 knockout mice. BMC Biol. 5:42. doi: 10.1186/17417007-5-42

Duclot, F., and Kabbaj, M. (2017). The role of early growth response 1 (EGR1) in brain plasticity and neuropsychiatric disorders. Front. Behav. Neurosci. 11:35. doi: 10.3389/fnbeh.2017.00035

Dumoulin, M. C., Aton, S. J., Watson, A. J., Renouard, L., Coleman, T., and Frank, M. G. (2015). Extracellular signal-regulated kinase (ERK) activity during sleep consolidates cortical plasticity in vivo. Cereb. Cortex N.Y. 25, 507-515. doi: 10.1093/cercor/bht250

Durkin, J., and Aton, S. J. (2016). Sleep-dependent potentiation in the visual system is at odds with the synaptic homeostasis hypothesis. Sleep 39, 155-159. doi: $10.5665 /$ sleep. 5338 
Durkin, J., Suresh, A. K., Colbath, J., Broussard, C., Wu, J., Zochowski, M., et al. (2017). Cortically coordinated NREM thalamocortical oscillations play an essential, instructive role in visual system plasticity. Proc. Natl. Acad. Sci. U.S.A. 114, 10485-10490. doi: 10.1073/pnas.1710613114

Eckel-Mahan, K. L., Phan, T., Han, S., Wang, H., Chan, G. C. K., Scheiner, Z. S., et al. (2008). Circadian oscillation of hippocampal MAPK activity and cAmp: implications for memory persistence. Nat. Neurosci. 11, 1074-1082. doi: $10.1038 / \mathrm{nn} .2174$

El-Boustani, S., Ip, J. P. K., Breton-Provencher, V., Knott, G. W., Okuno, H., Bito, H., et al. (2018). Locally coordinated synaptic plasticity of visual cortex neurons in vivo. Science 360, 1349-1354. doi: 10.1126/science.aao0862

Eschenko, O., Mölle, M., Born, J., and Sara, S. J. (2006). Elevated sleep spindle density after learning or after retrieval in rats. J. Neurosci. Off. J. Soc. Neurosci. 26, 12914-12920. doi: 10.1523/JNEUROSCI.3175-06.2006

Espinosa, F., Marks, G., Heintz, N., and Joho, R. H. (2004). Increased motor drive and sleep loss in mice lacking Kv3-type potassium channels. Genes Brain Behav. 3, 90-100. doi: 10.1046/j.1601-183x.2003.00054.x

Espinosa, J. S., and Stryker, M. P. (2012). Development and plasticity of the primary visual cortex. Neuron 75, 230-249. doi: 10.1016/j.neuron.2012.06.009

Esteban, J. A., Shi, S.-H., Wilson, C., Nuriya, M., Huganir, R. L., and Malinow, R. (2003). PKA phosphorylation of AMPA receptor subunits controls synaptic trafficking underlying plasticity. Nat. Neurosci. 6, 136-143. doi: 10.1038/nn997

Euston, D. R., Tatsuno, M., and McNaughton, B. L. (2007). Fast-forward playback of recent memory sequences in prefrontal cortex during sleep. Science 318, 1147-1150. doi: 10.1126/science.1148979

Feig, S., and Lipton, P. (1993). Pairing the cholinergic agonist carbachol with patterned Schaffer collateral stimulation initiates protein synthesis in hippocampal CA1 pyramidal cell dendrites via a muscarinic, NMDA-dependent mechanism. J. Neurosci. Off. J. Soc. Neurosci. 13, 1010-1021. doi: 10.1523/ JNEUROSCI.13-03-01010.1993

Finsterwald, C., and Alberini, C. M. (2014). Stress and glucocorticoid receptordependent mechanisms in long-term memory: from adaptive responses to psychopathologies. Neurobiol. Learn. Mem. 112, 17-29. doi: 10.1016/j.nlm. 2013.09.017

Flavell, S. W., and Greenberg, M. E. (2008). Signaling mechanisms linking neuronal activity to gene expression and plasticity of the nervous system. Annu. Rev. Neurosci. 31, 563-590. doi: 10.1146/annurev.neuro.31.060407.125631

Frank, M. G. (2016). Circadian regulation of synaptic plasticity. Biology 5:31. doi: 10.3390/biology5030031

Frank, M. G., and Benington, J. H. (2006). The role of sleep in memory consolidation and brain plasticity: dream or reality? Neurosci. Rev. J. Bring. Neurobiol. Neurol. Psychiatry 12, 477-488. doi: 10.1177/1073858406293552

Frank, M. G., and Cantera, R. (2014). Sleep, clocks, and synaptic plasticity. Trends Neurosci. 37, 491-501. doi: 10.1016/j.tins.2014.06.005

Frenkel, M. Y., and Bear, M. F. (2004). How monocular deprivation shifts ocular dominance in visual cortex of young mice. Neuron 44, 917-923. doi: 10.1016/j. neuron.2004.12.003

Frey, S., and Frey, J. U. (2008). "Synaptic tagging" and "cross-tagging” and related associative reinforcement processes of functional plasticity as the cellular basis for memory formation. Prog. Brain Res. 169, 117-143. doi: 10.1016/S00796123(07)00007-6

Frey, U., and Morris, R. G. (1997). Synaptic tagging and long-term potentiation. Nature 385, 533-536. doi: 10.1038/385533a0

Frick, A., and Johnston, D. (2005). Plasticity of dendritic excitability. J. Neurobiol. 64, 100-115. doi: 10.1002/neu.20148

Gastaut, H., and Tassinari, C. A. (1966). Triggering mechanisms in epilepsy, the electroclinical point of view. Epilepsia 7, 85-138. doi: 10.1111/j.1528-1167.1966. tb06262.x

Genzel, L., Rossato, J. I., Jacobse, J., Grieves, R. M., Spooner, P. A., Battaglia, F. P., et al. (2017). The yin and yang of memory consolidation: hippocampal and neocortical. PLoS Biol. 15:e2000531. doi: 10.1371/journal.pbio.2000531

Gerstner, J. R., Koberstein, J. N., Watson, A. J., Zapero, N., Risso, D., Speed, T. P., et al. (2016). Removal of unwanted variation reveals novel patterns of gene expression linked to sleep homeostasis in murine cortex. BMC Genomics 17:727. doi: 10.1186/s12864-016-3065-8

Giuditta, A. (2014). Sleep memory processing: the sequential hypothesis. Front. Syst. Neurosci. 8:219. doi: 10.3389/fnsys.2014.00219
Giuditta, A., Ambrosini, M. V., Montagnese, P., Mandile, P., Cotugno, M., Grassi Zucconi, G., et al. (1995). The sequential hypothesis of the function of sleep. Behav. Brain Res. 69, 157-166. doi: 10.1016/0166-4328(95)00012-I

Govindarajan, A., Kelleher, R. J., and Tonegawa, S. (2006). A clustered plasticity model of long-term memory engrams. Nat. Rev. Neurosci. 7, 575-583. doi: $10.1038 /$ nrn 1937

Grønli, J., Soulé, J., and Bramham, C. R. (2014). Sleep and protein synthesisdependent synaptic plasticity: impacts of sleep loss and stress. Front. Behav. Neurosci. 7:224. doi: 10.3389/fnbeh.2013.00224

Grosmark, A. D., Mizuseki, K., Pastalkova, E., Diba, K., and Buzsáki, G. (2012). REM sleep reorganizes hippocampal excitability. Neuron 75, 1001-1007. doi: 10.1016/j.neuron.2012.08.015

Gulati, T., Ramanathan, D. S., Wong, C. C., and Ganguly, K. (2014). Reactivation of emergent task-related ensembles during slow-wave sleep after neuroprosthetic learning. Nat. Neurosci. 17, 1107-1113. doi: 10.1038/nn.3759

Hairston, I. S., Peyron, C., Denning, D. P., Ruby, N. F., Flores, J., Sapolsky, R. M., et al. (2004). Sleep deprivation effects on growth factor expression in neonatal rats: a potential role for BDNF in the mediation of delta power. J. Neurophysiol. 91, 1586-1595. doi: 10.1152/jn.00894.2003

Hanlon, E. C., Faraguna, U., Vyazovskiy, V. V., Tononi, G., and Cirelli, C. (2009). Effects of skilled training on sleep slow wave activity and cortical gene expression in the rat. Sleep 32, 719-729. doi: 10.1093/sleep/32.6.719

Hayashi, Y., Shi, S. H., Esteban, J. A., Piccini, A., Poncer, J. C., and Malinow, R. (2000). Driving AMPA receptors into synapses by LTP and CaMKII: requirement for GluR1 and PDZ domain interaction. Science 287, 2262-2267. doi: $10.1126 /$ science.287.5461.2262

Hengen, K. B., Torrado Pacheco, A., McGregor, J. N., Van Hooser, S. D., and Turrigiano, G. G. (2016). Neuronal firing rate homeostasis is inhibited by sleep and promoted by wake. Cell 165, 180-191. doi: 10.1016/j.cell.2016. 01.046

Hernandez, P. J., and Abel, T. (2008). The role of protein synthesis in memory consolidation: progress amid decades of debate. Neurobiol. Learn. Mem. 89, 293-311. doi: 10.1016/j.nlm.2007.09.010

Ho, V. M., Lee, J.-A., and Martin, K. C. (2011). The cell biology of synaptic plasticity. Science 334, 623-628. doi: 10.1126/science.1209236

Hofer, S. B., Mrsic-Flogel, T. D., Bonhoeffer, T., and Hübener, M. (2009). Experience leaves a lasting structural trace in cortical circuits. Nature 457, 313-317. doi: $10.1038 /$ nature 07487

Holt, C. E., and Schuman, E. M. (2013). The central dogma decentralized: new perspectives on RNA function and local translation in neurons. Neuron 80, 648-657. doi: 10.1016/j.neuron.2013.10.036

Huber, R., Esser, S. K., Ferrarelli, F., Massimini, M., Peterson, M. J., and Tononi, G. (2007a). TMS-induced cortical potentiation during wakefulness locally increases slow wave activity during sleep. PLoS One 2:e276. doi: 10.1371/ journal.pone.0000276

Huber, R., Tononi, G., and Cirelli, C. (2007b). Exploratory behavior, cortical BDNF expression, and sleep homeostasis. Sleep 30, 129-139. doi: 10.1093/sleep/30.2. 129

Huber, R., Ghilardi, M. F., Massimini, M., Ferrarelli, F., Riedner, B. A., Peterson, M. J., et al. (2006). Arm immobilization causes cortical plastic changes and locally decreases sleep slow wave activity. Nat. Neurosci. 9, 1169-1176. doi: $10.1038 / \mathrm{nn} 1758$

Huber, R., Ghilardi, M. F., Massimini, M., and Tononi, G. (2004). Local sleep and learning. Nature 430, 78-81. doi: 10.1038/nature02663

Huber, R., Mäki, H., Rosanova, M., Casarotto, S., Canali, P., Casali, A. G., et al. (2013). Human cortical excitability increases with time awake. Cereb. Cortex N. Y. N 1991, 332-338. doi: 10.1093/cercor/bhs014

Hulme, S. R., Jones, O. D., and Abraham, W. C. (2013). Emerging roles of metaplasticity in behaviour and disease. Trends Neurosci. 36, 353-362. doi: 10.1016/j.tins.2013.03.007

Jakkamsetti, V., Tsai, N.-P., Gross, C., Molinaro, G., Collins, K. A., Nicoletti, F., et al. (2013). Experience-induced Arc/Arg3.1 primes CA1 pyramidal neurons for metabotropic glutamate receptor-dependent long-term synaptic depression. Neuron 80, 72-79. doi: 10.1016/j.neuron.2013.07.020

Ji, D., and Wilson, M. A. (2007). Coordinated memory replay in the visual cortex and hippocampus during sleep. Nat. Neurosci. 10, 100-107. doi: 10.1038/ nn 1825 
Johnson, L. A., Blakely, T., Hermes, D., Hakimian, S., Ramsey, N. F., and Ojemann, J. G. (2012). Sleep spindles are locally modulated by training on a brain-computer interface. Proc. Natl. Acad. Sci. U.S.A. 109, 18583-18588. doi: 10.1073/pnas.1207532109

Jouvet-Mounier, D., Astic, L., and Lacote, D. (1970). Ontogenesis of the states of sleep in rat, cat, and guinea pig during the first postnatal month. Dev. Psychobiol. 2, 216-239. doi: 10.1002/dev.420020407

Kastellakis, G., Cai, D. J., Mednick, S. C., Silva, A. J., and Poirazi, P. (2015). Synaptic clustering within dendrites: an emerging theory of memory formation. Prog. Neurobiol. 126, 19-35. doi: 10.1016/j.pneurobio.2014.12.002

Koh, K., Joiner, W. J., Wu, M. N., Yue, Z., Smith, C. J., and Sehgal, A. (2008). Identification of SLEEPLESS, a sleep-promoting factor. Science 321, 372-376. doi: 10.1126/science.1155942

Lang, C., Barco, A., Zablow, L., Kandel, E. R., Siegelbaum, S. A., and Zakharenko, S. S. (2004). Transient expansion of synaptically connected dendritic spines upon induction of hippocampal long-term potentiation. Proc. Natl. Acad. Sci. U.S.A. 101, 16665-16670. doi: 10.1073/pnas.0407581101

Levenstein, D., Watson, B. O., Rinzel, J., and Buzsáki, G. (2017). Sleep regulation of the distribution of cortical firing rates. Curr. Opin. Neurobiol. 44, 34-42. doi: 10.1016/j.conb.2017.02.013

Lewis, P. A., Knoblich, G., and Poe, G. (2018). How memory replay in sleep boosts creative problem-solving. Trends Cogn. Sci. 22, 491-503. doi: 10.1016/j.tics. 2018.03.009

Li, W., Ma, L., Yang, G., and Gan, W.-B. (2017). REM sleep selectively prunes and maintains new synapses in development and learning. Nat. Neurosci. 20, 427-437. doi: 10.1038/nn.4479

Lisman, J., Cooper, K., Sehgal, M., and Silva, A. J. (2018). Memory formation depends on both synapse-specific modifications of synaptic strength and cellspecific increases in excitability. Nat. Neurosci. 21, 309-314. doi: 10.1038/ s41593-018-0076-6

Liston, C., Cichon, J. M., Jeanneteau, F., Jia, Z., Chao, M. V., and Gan, W.B. (2013). Circadian glucocorticoid oscillations promote learning-dependent synapse formation and maintenance. Nat. Neurosci. 16, 698-705. doi: 10.1038/ nn. 3387

Liston, C., and Gan, W.-B. (2011). Glucocorticoids are critical regulators of dendritic spine development and plasticity in vivo. Proc. Natl. Acad. Sci. U.S.A. 108, 16074-16079. doi: 10.1073/pnas.1110444108

Lopezde Armentia, M., Jancic, D., Olivares, R., Alarcon, J. M., Kandel, E. R., and Barco, A. (2007). cAMP response element-binding protein-mediated gene expression increases the intrinsic excitability of CA1 pyramidal neurons. J. Neurosci. Off. J. Soc. Neurosci. 27, 13909-13918. doi: 10.1523/JNEUROSCI. 3850-07.2007

Losonczy, A., Makara, J. K., and Magee, J. C. (2008). Compartmentalized dendritic plasticity and input feature storage in neurons. Nature 452, 436-441. doi: 10.1038/nature06725

Luo, J., Phan, T. X., Yang, Y., Garelick, M. G., and Storm, D. R. (2013). Increases in CAMP, MAPK activity, and CREB phosphorylation during REM sleep: implications for REM sleep and memory consolidation. J. Neurosci. Off. J. Soc. Neurosci. 33, 6460-6468. doi: 10.1523/JNEUROSCI.5018-12.2013

Ly, J. Q., Gaggioni, G., Chellappa, S. L., Papachilleos, S., Brzozowski, A., Borsu, C., et al. (2016). Circadian regulation of human cortical excitability. Nat. Commun. 7:11828. doi: $10.1038 /$ ncomms 11828

Mackiewicz, M., Shockley, K. R., Romer, M. A., Galante, R. J., Zimmerman, J. E., Naidoo, N., et al. (2007). Macromolecule biosynthesis: a key function of sleep. Physiol. Genomics 31, 441-457. doi: 10.1152/physiolgenomics.00275.2006

Maret, S., Faraguna, U., Nelson, A. B., Cirelli, C., and Tononi, G. (2011). Sleep and waking modulate spine turnover in the adolescent mouse cortex. Nat. Neurosci. 14, 1418-1420. doi: 10.1038/nn.2934

Meisel, C., Schulze-Bonhage, A., Freestone, D., Cook, M. J., Achermann, P., and Plenz, D. (2015). Intrinsic excitability measures track antiepileptic drug action and uncover increasing/decreasing excitability over the wake/sleep cycle. Proc. Natl. Acad. Sci. U.S.A. 112, 14694-14699. doi: 10.1073/pnas.1513716112

Meyer, D., Bonhoeffer, T., and Scheuss, V. (2014). Balance and stability of synaptic structures during synaptic plasticity. Neuron $82,430-443$. doi: 10.1016/ j.neuron.2014.02.031

Minatohara, K., Akiyoshi, M., and Okuno, H. (2016). Role of immediate-early genes in synaptic plasticity and neuronal ensembles underlying the memory trace. Front. Mol. Neurosci. 8:78. doi: 10.3389/fnmol.2015.00078
Miyawaki, H., and Diba, K. (2016). Regulation of hippocampal firing by network oscillations during sleep. Curr. Biol. 26, 893-902. doi: 10.1016/j.cub.2016.02.024

Mölle, M., Eschenko, O., Gais, S., Sara, S. J., and Born, J. (2009). The influence of learning on sleep slow oscillations and associated spindles and ripples in humans and rats. Eur. J. Neurosci. 29, 1071-1081. doi: 10.1111/j.1460-9568. 2009.06654.x

Moncada, D., Ballarini, F., Martinez, M. C., Frey, J. U., and Viola, H. (2011). Identification of transmitter systems and learning tag molecules involved in behavioral tagging during memory formation. Proc. Natl. Acad. Sci. U.S.A. 108, 12931-12936. doi: 10.1073/pnas.1104495108

Naidoo, N. (2012). Roles of endoplasmic reticulum and energetic stress in disturbed sleep. Neuromol. Med. 14, 213-219. doi: 10.1007/s12017-012-8179-9

Naidoo, N., Ferber, M., Master, M., Zhu, Y., and Pack, A. I. (2008). Aging impairs the unfolded protein response to sleep deprivation and leads to proapoptotic signaling. J. Neurosci. Off. J. Soc. Neurosci. 28, 6539-6548. doi: 10.1523/ JNEUROSCI.5685-07.2008

Naidoo, N., Giang, W., Galante, R. J., and Pack, A. I. (2005). Sleep deprivation induces the unfolded protein response in mouse cerebral cortex. J. Neurochem. 92, 1150-1157. doi: 10.1111/j.1471-4159.2004.02952.x

Nakanishi, H., Sun, Y., Nakamura, R. K., Mori, K., Ito, M., Suda, S., et al. (1997). Positive correlations between cerebral protein synthesis rates and deep sleep in Macaca mulatta. Eur. J. Neurosci. 9, 271-279. doi: 10.1111/j.1460-9568.1997. tb01397.x

Navarro-Lobato, I., and Genzel, L. (2018). The up and down of sleep: from molecules to electrophysiology. Neurobiol. Learn. Mem. [Epub ahead of print]. doi: 10.1016/j.nlm.2018.03.013

Nelson, S. E., Duricka, D. L., Campbell, K., Churchill, L., and Krueger, J. M. (2004). Homerla and $1 \mathrm{bc}$ levels in the rat somatosensory cortex vary with the time of day and sleep loss. Neurosci. Lett. 367, 105-108. doi: 10.1016/j.neulet.2004.05. 089

Nikolaienko, O., Patil, S., Eriksen, M. S., and Bramham, C. R. (2018). Arc protein: a flexible hub for synaptic plasticity and cognition. Semin. Cell Dev. Biol. 77, 33-42. doi: 10.1016/j.semcdb.2017.09.006

Norimoto, H., Makino, K., Gao, M., Shikano, Y., Okamoto, K., Ishikawa, T., et al. (2018). Hippocampal ripples down-regulate synapses. Science 359, 1524-1527. doi: $10.1126 /$ science.aao0702

Noya, S. (2018). The cortical synaptic transcriptome isorganized by clocks, but its proteome is drivenby sleep. Basel J. Sleep Res. 27:17.

Ognjanovski, N., Broussard, C., Zochowski, M., and Aton, S. J. (2018). Hippocampal network oscillations rescue memory consolidation deficits caused by sleep loss. Cereb. Cortex N. Y. 28, 3711-3723. doi: 10.1093/cercor/bhy174

Ognjanovski, N., Schaeffer, S., Wu, J., Mofakham, S., Maruyama, D., Zochowski, M., et al. (2017). Parvalbumin-expressing interneurons coordinate hippocampal network dynamics required for memory consolidation. Nat. Commun. 8:15039. doi: 10.1038/ncomms15039

Okada, D., Ozawa, F., and Inokuchi, K. (2009). Input-specific spine entry of somaderived Vesl-1S protein conforms to synaptic tagging. Science 324, 904-909. doi: $10.1126 /$ science. 1171498

Okamoto, K., Bosch, M., and Hayashi, Y. (2009). The roles of CaMKII and F-actin in the structural plasticity of dendritic spines: a potential molecular identity of a synaptic tag? Physioloy 24, 357-366. doi: 10.1152/physiol.00029.2009

Okuno, H., Akashi, K., Ishii, Y., Yagishita-Kyo, N., Suzuki, K., Nonaka, M., et al. (2012). Inverse synaptic tagging of inactive synapses via dynamic interaction of Arc/Arg3.1 with CaMKIIB. Cell 149, 886-898. doi: 10.1016/j.cell.2012.02.062

Ostroff, L. E., Watson, D. J., Cao, G., Parker, P. H., Smith, H., and Harris, K. M. (2018). Shifting patterns of polyribosome accumulation at synapses over the course of hippocampal long-term potentiation. Hippocampus 28, 416-430. doi: 10.1002/hipo.22841

Panja, D., and Bramham, C. R. (2014). BDNF mechanisms in late LTP formation: a synthesis and breakdown. Neuropharmacology 76(Pt C), 664-676. doi: 10.1016/ j.neuropharm.2013.06.024

Poe, G. R., Walsh, C. M., and Bjorness, T. E. (2010). Cognitive neuroscience of sleep. Prog. Brain Res. 185, 1-19. doi: 10.1016/B978-0-444-53702-7.00001-4

Pompeiano, M., Cirelli, C., Ronca-Testoni, S., and Tononi, G. (1997). NGFI-A expression in the rat brain after sleep deprivation. Brain Res. Mol. Brain Res. 46, 143-153. doi: 10.1016/S0169-328X(96)00295-1

Pompeiano, M., Cirelli, C., and Tononi, G. (1994). Immediate-early genes in spontaneous wakefulness and sleep: expression of c-fos and NGFI-A mRNA 
and protein. J. Sleep Res. 3, 80-96. doi: 10.1111/j.1365-2869.1994.tb0\{\break\} 0111.x

Popov, V. I., Davies, H. A., Rogachevsky, V. V., Patrushev, I. V., Errington, M. L., Gabbott, P. L. A., et al. (2004). Remodelling of synaptic morphology but unchanged synaptic density during late phase long-term potentiation (LTP): a serial section electron micrograph study in the dentate gyrus in the anaesthetised rat. Neuroscience 128, 251-262. doi: 10.1016/j.neuroscience.2004. 06.029

Puentes-Mestril, C., and Aton, S. J. (2017). Linking network activity to synaptic plasticity during sleep: hypotheses and recent data. Front. Neural Circuits 11:61. doi: 10.3389/fncir.2017.00061

Ramm, P., and Smith, C. T. (1990). Rates of cerebral protein synthesis are linked to slow wave sleep in the rat. Physiol. Behav. 48, 749-753. doi: 10.1016/00319384(90)90220-X

Rasch, B., and Born, J. (2013). About sleep's role in memory. Physiol. Rev. 93, 681-766. doi: 10.1152/physrev.00032.2012

Redondo, R. L., and Morris, R. G. M. (2011). Making memories last: the synaptic tagging and capture hypothesis. Nat. Rev. Neurosci. 12, 17-30. doi: 10.1038/ nrn2963

Redondo, R. L., Okuno, H., Spooner, P. A., Frenguelli, B. G., Bito, H., and Morris, R. G. M. (2010). Synaptic tagging and capture: differential role of distinct calcium/calmodulin kinases in protein synthesis-dependent long-term potentiation. J. Neurosci. Off. J. Soc. Neurosci. 30, 4981-4989. doi: 10.1523/ JNEUROSCI.3140-09.2010

Renouard, L., Bridi, M. C. D., Coleman, T., Arckens, L., and Frank, M. G. (2018). Anatomical correlates of rapid eye movement sleep-dependent plasticity in the developing cortex. Sleep 41. doi: 10.1093/sleep/zsy124

Ribeiro, S., Goyal, V., Mello, C. V., and Pavlides, C. (1999). Brain gene expression during REM sleep depends on prior waking experience. Learn. Mem. 6, 500508. doi: 10.1101/lm.6.5.500

Ribeiro, S., Mello, C. V., Velho, T., Gardner, T. J., Jarvis, E. D., and Pavlides, C. (2002). Induction of hippocampal long-term potentiation during waking leads to increased extrahippocampal zif-268 expression during ensuing rapid-eyemovement sleep. J. Neurosci. Off. J. Soc. Neurosci. 22, 10914-10923. doi: 10. 1523/JNEUROSCI.22-24-10914.2002

Ribeiro, S., and Nicolelis, M. A. L. (2004). Reverberation, storage, and postsynaptic propagation of memories during sleep. Learn. Mem. 11, 686-696. doi: 10.1101/ $\operatorname{lm} .75604$

Ribeiro, S., Shi, X., Engelhard, M., Zhou, Y., Zhang, H., Gervasoni, D., et al. (2007). Novel experience induces persistent sleep-dependent plasticity in the cortex but not in the hippocampus. Front. Neurosci. 1:43-55. doi: 10.3389/neuro.01.1.1. 003.2007

Richter, J. D., and Sonenberg, N. (2005). Regulation of cap-dependent translation by eIF4E inhibitory proteins. Nature 433, 477-480. doi: 10.1038/nature03205

Rogerson, T., Cai, D. J., Frank, A., Sano, Y., Shobe, J., Lopez-Aranda, M. F., et al. (2014). Synaptic tagging during memory allocation. Nat. Rev. Neurosci. 15, 157-169. doi: 10.1038/nrn3667

Rosanova, M., and Ulrich, D. (2005). Pattern-specific associative long-term potentiation induced by a sleep spindle-related spike train. J. Neurosci. Off. J. Soc. Neurosci. 25, 9398-9405. doi: 10.1523/JNEUROSCI.2149-05.2005

Sadowski, J. H. L. P., Jones, M. W., and Mellor, J. R. (2016). Sharp-wave ripples orchestrate the induction of synaptic plasticity during reactivation of place cell firing patterns in the hippocampus. Cell Rep. 14, 1916-1929. doi: 10.1016/j. celrep.2016.01.061

Sajikumar, S., and Korte, M. (2011). Metaplasticity governs compartmentalization of synaptic tagging and capture through brain-derived neurotrophic factor (BDNF) and protein kinase Mzeta (PKMzeta). Proc. Natl. Acad. Sci. U.S.A. 108, 2551-2556. doi: 10.1073/pnas.1016849108

Sajikumar, S., Li, Q., Abraham, W. C., and Xiao, Z. C. (2009). Priming of short-term potentiation and synaptic tagging/capture mechanisms by ryanodine receptor activation in rat hippocampal CA1. Learn. Mem. 16, 178-186. doi: 10.1101/lm. 1255909

Sanders, J., Cowansage, K., Baumgärtel, K., and Mayford, M. (2012). Elimination of dendritic spines with long-term memory is specific to active circuits. J. Neurosci. Off. J. Soc. Neurosci. 32, 12570-12578. doi: 10.1523/JNEUROSCI.1131- 12.2012

Sandler, M., Shulman, Y., and Schiller, J. (2016). A novel form of local plasticity in tuft dendrites of neocortical somatosensory layer 5 pyramidal neurons. Neuron 90, 1028-1042. doi: 10.1016/j.neuron.2016.04.032
Schmidt, M. V., Abraham, W. C., Maroun, M., Stork, O., and Richter-Levin, G. (2013). Stress-induced metaplasticity: from synapses to behavior. Neuroscience 250, 112-120. doi: 10.1016/j.neuroscience.2013.06.059

Seibt, J., Dumoulin, M. C., Aton, S. J., Coleman, T., Watson, A., Naidoo, N., et al. (2012). Protein synthesis during sleep consolidates cortical plasticity in vivo. Curr. Biol. 22, 676-682. doi: 10.1016/j.cub.2012.02.016

Seibt, J., Richard, C. J., Sigl-Glöckner, J., Takahashi, N., Kaplan, D. I., Doron, G., et al. (2017). Cortical dendritic activity correlates with spindle-rich oscillation during sleep in rodents. Nat. Commun. 8:684. doi: 10.1038/s41467-01700735-w

Semba, K., Pastorius, J., Wilkinson, M., and Rusak, B. (2001). Sleep deprivationinduced c-fos and junB expression in the rat brain: effects of duration and timing. Behav. Brain Res. 120, 75-86. doi: 10.1016/S0166-4328(00)00362-4

Shah, M. M. (2014). Cortical HCN channels: function, trafficking and plasticity. J. Physiol. 592, 2711-2719. doi: 10.1113/jphysiol.2013.270058

Siapas, A. G., and Wilson, M. A. (1998). Coordinated interactions between hippocampal ripples and cortical spindles during slow-wave sleep. Neuron 21 , 1123-1128. doi: 10.1016/S0896-6273(00)80629-7

Siddoway, B., Hou, H., and Xia, H. (2014). Molecular mechanisms of homeostatic synaptic downscaling. Neuropharmacology 78, 38-44. doi: 10.1016/ j.neuropharm.2013.07.009

Sigl-Glöckner, J., and Seibt, J. (2018). Peeking into the sleeping brain: using in vivo imaging in rodents to understand the relationship between sleep and cognition. J. Neurosci. Methods [Epub ahead of print]. doi: 10.1016/j.jneumeth.2018.09.011

Silva, A. J., Zhou, Y., Rogerson, T., Shobe, J., and Balaji, J. (2009). Molecular and cellular approaches to memory allocation in neural circuits. Science 326, 391-395. doi: 10.1126/science.1174519

Spruston, N. (2008). Pyramidal neurons: dendritic structure and synaptic integration. Nat. Rev. Neurosci. 9, 206-221. doi: 10.1038/nrn2286

Steenland, H. W., Wu, V., Fukushima, H., Kida, S., and Zhuo, M. (2010). CaMKIV over-expression boosts cortical 4-7 Hz oscillations during learning and 1-4 Hz delta oscillations during sleep. Mol. Brain 3:16. doi: 10.1186/1756-6606-3-16

Steriade, M., and Timofeev, I. (2003). Neuronal plasticity in thalamocortical networks during sleep and waking oscillations. Neuron 37, 563-576. doi: 10.1016/S0896-6273(03)00065-5

Stickgold, R., and Walker, M. P. (2013). Sleep-dependent memory triage: evolving generalization through selective processing. Nat. Neurosci. 16, 139-145. doi: 10.1038/nn.3303

Szabó, E. C., Manguinhas, R., and Fonseca, R. (2016). The interplay between neuronal activity and actin dynamics mimic the setting of an LTD synaptic tag. Sci. Rep. 6:33685. doi: 10.1038/srep33685

Taishi, P., Sanchez, C., Wang, Y., Fang, J., Harding, J. W., and Krueger, J. M. (2001). Conditions that affect sleep alter the expression of molecules associated with synaptic plasticity. Am. J. Physiol. Regul. Integr. Comp. Physiol. 281, R839-R845. doi: 10.1152/ajpregu.2001.281.3.R839

Terao, A., Greco, M. A., Davis, R. W., Heller, H. C., and Kilduff, T. S. (2003). Region-specific changes in immediate early gene expression in response to sleep deprivation and recovery sleep in the mouse brain. Neuroscience 120, 1115-1124. doi: 10.1016/S0306-4522(03)00395-6

Terao, A., Wisor, J. P., Peyron, C., Apte-Deshpande, A., Wurts, S. W., Edgar, D. M., et al. (2006). Gene expression in the rat brain during sleep deprivation and recovery sleep: an Affymetrix GeneChip study. Neuroscience 137, 593-605. doi: 10.1016/j.neuroscience.2005.08.059

Thompson, C. L., Wisor, J. P., Lee, C.-K., Pathak, S. D., Gerashchenko, D., Smith, K. A., et al. (2010). Molecular and anatomical signatures of sleep deprivation in the mouse brain. Front. Neurosci. 4:165. doi: 10.3389/fnins.2010. 00165

Timofeev, I., Grenier, F., Bazhenov, M., Houweling, A. R., Sejnowski, T. J., and Steriade, M. (2002). Short- and medium-term plasticity associated with augmenting responses in cortical slabs and spindles in intact cortex of cats in vivo. J. Physiol. 542, 583-598. doi: 10.1113/jphysiol.2001.013479

Tononi, G., and Cirelli, C. (2003). Sleep and synaptic homeostasis: a hypothesis. Brain Res. Bull. 62, 143-150. doi: 10.1016/j.brainresbull.2003.09.004

Tononi, G., and Cirelli, C. (2006). Sleep function and synaptic homeostasis. Sleep Med. Rev. 10, 49-62. doi: 10.1016/j.smrv.2005.05.002

Tononi, G., and Cirelli, C. (2014). Sleep and the price of plasticity: from synaptic and cellular homeostasis to memory consolidation and integration. Neuron 81 , 12-34. doi: 10.1016/j.neuron.2013.12.025 
Tudor, J. C., Davis, E. J., Peixoto, L., Wimmer, M. E., van Tilborg, E., Park, A. J., et al. (2016). Sleep deprivation impairs memory by attenuating mTORC1-dependent protein synthesis. Sci. Signal. 9:e13424. doi: 10.1126/scisignal.aad4949

Turrigiano, G. G. (2008). The self-tuning neuron: synaptic scaling of excitatory synapses. Cell 135, 422-435. doi: 10.1016/j.cell.2008.10.008

Ulloor, J., and Datta, S. (2005). Spatio-temporal activation of cyclic AMP response element-binding protein, activity-regulated cytoskeletal-associated protein and brain-derived nerve growth factor: a mechanism for pontine-wave generator activation-dependent two-way active-avoidance memory processing in the rat. J. Neurochem. 95, 418-428. doi: 10.1111/j.1471-4159.2005.03378.x

Ulrich, D. (2016). Sleep spindles as facilitators of memory formation and learning. Neural Plast. 2016:1796715. doi: 10.1155/2016/1796715

Vecsey, C. G., Baillie, G. S., Jaganath, D., Havekes, R., Daniels, A., Wimmer, M., et al. (2009). Sleep deprivation impairs cAMP signalling in the hippocampus. Nature 461, 1122-1125. doi: 10.1038/nature08488

Vecsey, C. G., Peixoto, L., Choi, J. H. K., Wimmer, M., Jaganath, D., Hernandez, P. J., et al. (2012). Genomic analysis of sleep deprivation reveals translational regulation in the hippocampus. Physiol. Genomics 44, 981-991. doi: 10.1152/ physiolgenomics.00084.2012

Veyrac, A., Besnard, A., Caboche, J., Davis, S., and Laroche, S. (2014). The transcription factor Zif268/Egr1, brain plasticity, and memory. Prog. Mol. Biol. Transl. Sci. 122, 89-129. doi: 10.1016/B978-0-12-420170-5.00004-0

Viosca, J., Lopezde Armentia, M., Jancic, D., and Barco, A. (2009). Enhanced CREB-dependent gene expression increases the excitability of neurons in the basal amygdala and primes the consolidation of contextual and cued fear memory. Learn. Mem. 16, 193-197. doi: 10.1101/lm.1254209

Vivo, L., deBellesi, M., Marshall, W., Bushong, E. A., Ellisman, M. H., Tononi, G., et al. (2017). Ultrastructural evidence for synaptic scaling across the wake/sleep cycle. Science 355, 507-510. doi: 10.1126/science.aah5982

Vyazovskiy, V., Borbély, A. A., and Tobler, I. (2000). Unilateral vibrissae stimulation during waking induces interhemispheric EEG asymmetry during subsequent sleep in the rat. J. Sleep Res. 9, 367-371. doi: 10.1046/j.1365-2869. 2000.00230.x

Vyazovskiy, V. V., Cirelli, C., Pfister-Genskow, M., Faraguna, U., and Tononi, G. (2008). Molecular and electrophysiological evidence for net synaptic potentiation in wake and depression in sleep. Nat. Neurosci. 11, 200-208. doi: $10.1038 / \mathrm{nn} 2035$

Vyazovskiy, V. V., and Harris, K. D. (2013). Sleep and the single neuron: the role of global slow oscillations in individual cell rest. Nat. Rev. Neurosci. 14, 443-451. doi: 10.1038/nrn3494

Vyazovskiy, V. V., Olcese, U., Cirelli, C., and Tononi, G. (2013). Prolonged wakefulness alters neuronal responsiveness to local electrical stimulation of the neocortex in awake rats. J. Sleep Res. 22, 239-250. doi: 10.1111/jsr.12009

Vyazovskiy, V. V., Olcese, U., Lazimy, Y. M., Faraguna, U., Esser, S. K., Williams, J. C., et al. (2009). Cortical firing and sleep homeostasis. Neuron 63, 865-878. doi: 10.1016/j.neuron.2009.08.024

Wang, Z., Ma, J., Miyoshi, C., Li, Y., Sato, M., Ogawa, Y., et al. (2018). Quantitative phosphoproteomic analysis of the molecular substrates of sleep need. Nature 558, 435-439. doi: 10.1038/s41586-018-0218-8

Watson, B. O., Levenstein, D., Greene, J. P., Gelinas, J. N., and Buzsáki, G. (2016). Network homeostasis and state dynamics of neocortical sleep. Neuron 90, 839-852. doi: 10.1016/j.neuron.2016.03.036

Wilkerson, J. R., Albanesi, J. P., and Huber, K. M. (2018). Roles for Arc in metabotropic glutamate receptor-dependent LTD and synapse elimination: implications in health and disease. Semin. Cell Dev. Biol. 77, 51-62. doi: 10.1016/j.semcdb.2017.09.035

Williams, S. R., Wozny, C., and Mitchell, S. J. (2007). The back and forth of dendritic plasticity. Neuron 56, 947-953. doi: 10.1016/j.neuron.2007. 12.004
Winters, B. D., Huang, Y. H., Dong, Y., and Krueger, J. M. (2011). Sleep loss alters synaptic and intrinsic neuronal properties in mouse prefrontal cortex. Brain Res. 1420, 1-7. doi: 10.1016/j.brainres.2011.08.078

Wu, M., Robinson, J. E., and Joiner, W. J. (2014). SLEEPLESS is a bifunctional regulator of excitability and cholinergic synaptic transmission. Curr. Biol. 24, 621-629. doi: 10.1016/j.cub.2014.02.026

Xu, J., Kang, N., Jiang, L., Nedergaard, M., and Kang, J. (2005). Activitydependent long-term potentiation of intrinsic excitability in hippocampal CA1 pyramidal neurons. J. Neurosci. Off. J. Soc. Neurosci. 25, 1750-1760. doi: 10.1523/JNEUROSCI.4217-04.2005

Xu, T., Yu, X., Perlik, A. J., Tobin, W. F., Zweig, J. A., Tennant, K., et al. (2009). Rapid formation and selective stabilization of synapses for enduring motor memories. Nature 462, 915-919. doi: 10.1038/nature08389

Yan, J., Li, J.-C., Xie, M.-L., Zhang, D., Qi, A.-P., Hu, B., et al. (2011). Short-term sleep deprivation increases intrinsic excitability of prefrontal cortical neurons. Brain Res. 1401, 52-58. doi: 10.1016/j.brainres.2011.05.032

Yang, G., and Gan, W.-B. (2012). Sleep contributes to dendritic spine formation and elimination in the developing mouse somatosensory cortex. Dev. Neurobiol. 72, 1391-1398. doi: 10.1002/dneu.20996

Yang, G., Lai, C. S. W., Cichon, J., Ma, L., Li, W., and Gan, W.-B. (2014). Sleep promotes branch-specific formation of dendritic spines after learning. Science 344, 1173-1178. doi: 10.1126/science.1249098

Yang, G., Pan, F., and Gan, W.-B. (2009). Stably maintained dendritic spines are associated with lifelong memories. Nature 462, 920-924. doi: 10.1038/ nature08577

Yang, Y., Wang, X.-B., Frerking, M., and Zhou, Q. (2008). Delivery of AMPA receptors to perisynaptic sites precedes the full expression of long-term potentiation. Proc. Natl. Acad. Sci. U.S.A. 105, 11388-11393. doi: 10.1073/pnas. 0802978105

Yee, A. X., Hsu, Y.-T., and Chen, L. (2017). A metaplasticity view of the interaction between homeostatic and Hebbian plasticity. Philos. Trans. R. Soc. Lond. B. Biol. Sci. 372:20160155. doi: 10.1098/rstb.2016.0155

Young, J. Z., Isiegas, C., Abel, T., and Nguyen, P. V. (2006). Metaplasticity of the late-phase of long-term potentiation: a critical role for protein kinase A in synaptic tagging. Eur. J. Neurosci. 23, 1784-1794. doi: 10.1111/j.1460-9568. 2006.04707.x

Yu, X., Wang, G., Gilmore, A., Yee, A. X., Li, X., Xu, T., et al. (2013). Accelerated experience-dependent pruning of cortical synapses in ephrin-A2 knockout mice. Neuron 80, 64-71. doi: 10.1016/j.neuron.2013.07.014

Zhou, Q., Homma, K. J., and Poo, M. (2004). Shrinkage of dendritic spines associated with long-term depression of hippocampal synapses. Neuron 44, 749-757. doi: 10.1016/j.neuron.2004.11.011

Zhou, Y., Won, J., Karlsson, M. G., Zhou, M., Rogerson, T., Balaji, J., et al. (2009). CREB regulates excitability and the allocation of memory to subsets of neurons in the amygdala. Nat. Neurosci. 12, 1438-1443. doi: 10.1038/nn.2405

Zuo, Y., Yang, G., Kwon, E., and Gan, W.-B. (2005). Long-term sensory deprivation prevents dendritic spine loss in primary somatosensory cortex. Nature 436, 261-265. doi: 10.1038/nature03715

Conflict of Interest Statement: The authors declare that the research was conducted in the absence of any commercial or financial relationships that could be construed as a potential conflict of interest.

Copyright (c) 2019 Seibt and Frank. This is an open-access article distributed under the terms of the Creative Commons Attribution License (CC BY). The use, distribution or reproduction in other forums is permitted, provided the original author(s) and the copyright owner(s) are credited and that the original publication in this journal is cited, in accordance with accepted academic practice. No use, distribution or reproduction is permitted which does not comply with these terms. 